\title{
Electronic Supplement of The Inaugural Meeting of The World Society for Pediatric and Congenital Heart Surgery
}

\author{
Jeffrey Phillip Jacobs ${ }^{1}$, Christo I. Tchervenkov ${ }^{2}$, Richard A. Jonas ${ }^{3}$, Giovanni Stellin ${ }^{4}$, Hiromi Kurosawa ${ }^{5}$, \\ Constantine Mavroudis ${ }^{6}$, Sertac M. Cicek ${ }^{7}$, Robert H. Anderson ${ }^{8}$ \\ ${ }^{1}$ The Congenital Heart Institute of Florida, All Children's Hospital, Children's Hospital of Tampa, University of \\ South Florida, St Petersburg and Tampa, Florida, United States of America; ${ }^{2}$ Montreal Children's Hospital, McGill \\ University, Montreal, Quebec, Canada; ${ }^{3}$ Children's National Medical Center, Washington DC, United States of \\ America; ${ }^{4}$ University of Padova Medical School, Padova, Italy; ${ }^{5}$ Heart Institute of Japan, Tokyo Women's Medical \\ University, Tokyo, Japan; ${ }^{6}$ Children's Memorial Hospital, Northwestern University Feinberg School of Medicine, \\ Chicago, Illinois, United States of America; ${ }^{7}$ Siyami Ersek Thoracic E Cardiovascular Surgery Center Istanbul, Turkey; \\ ${ }^{8}$ Institute of Child Health, University College, London, United Kingdom
}

$\mathrm{T}$ He World SOCIETy for Pediatric and Congenital Heart Surgery will hold its inaugural meeting on Thursday, May 3, and Friday, May 4, 2007 in Washington, District of Columbia, hosted by Richard A. Jonas. Christo I. Tchervenkov, of Montreal, Canada, is the founding President of this newly formed society. The remaining officers are shown in Table 1.

As of April 19, 2007, the World Society has 423 Founding Members from 66 countries (Appendix 1). The Founding Members include 392 members who have joined the World Society and 31 special Honorary Founding Members (Appendix 2). Registration for the inaugural meeting stands at 302 registrants representing 61 countries. The meeting features a postgraduate course over the first day, devoted to tetralogy of Fallot, with the scientific session for the second day including 18 oral presentations. The presentations were selected from 90 abstracts submitted for consideration for presentation at the scientific session. In this electronic Supplement to Cardiology in the Young, we include the text of the 18 abstracts selected for oral

Correspondence to: Jeffrey P. Jacobs, MD, FACS, FACC, FCCP, Cardiovascular and Thoracic Surgeon, The Congenital Heart Institute of Florida (CHIF), Clinical Associate Professor, University of South Florida (USF), Cardiac Surgical Associates (CSA), 603 Seventh Street South, Suite 450, Saint Petersburg, FL 33701, United States of America. Office Phone: +727 8226666 ; Office Fax: +727821 5994; Cell Phone: +7272353100; E-mail: JeffJacobs@msn.com; http://www.heartsurgery-csa.com/, http://www.CHIF.us/
Table 1. Executive Committee of The World Society for Pediatric and Congenital Heart Surgery

\begin{tabular}{ll} 
President & Christo I. Tchervenkov, Montreal, Canada \\
1stVice-President & Giovanni Stellin, Padova, Italy \\
2ndVice-President & Hiromi Kurosawa, Tokyo, Japan \\
Secretary & Jeffrey P. Jacobs, St. Petersburg, United \\
Treasurer & States of America \\
& $\begin{array}{l}\text { Constantine Mavroudis, Chicago, United } \\
\text { States of America }\end{array}$ \\
\hline
\end{tabular}

presentation, as well as the 22 most outstanding presentations selected to be displayed as posters.

The World Society takes its origin from the highly successful first joint meeting of the Congenital Heart Surgeons' Society and the European Congenital Heart Surgeons Association, held in Montréal, Canada, through October 2 and $42004 .^{1}$ This meeting was organized by Christo I. Tchervenkov during the Centennial celebrations of the Montreal Children's Hospital, and was dedicated to the memory of John W. Kirklin, a remarkable pioneer of cardiac surgery who had died earlier in 2004. During this 3-day event, two genuine Canadian pioneers of cardiac surgery were also honoured, namely Anthony R.C. Dobell from Montréal, and George A. Trusler from Toronto, both long-time friends of John Kirklin. The joint meeting was attended by a total of 127 physicians, made up of 57 members of the Congenital Heart 
Surgeons Society, including the 2 Featured Guest Speakers and 10 new members, 25 members of the European Congenital Heart Surgeons Association, the 2 Honoured Guests, 29 surgeons sponsored as guests, and 14 local guests from Montreal Children's Hospital. At this Joint Meeting, initial discussions took place about the possibility of creating the World Society (Table 2).

On Tuesday, September 20, 2005, during the Fourth World Congress of Pediatric Cardiology and

Table 2. The Program Committee of The First Joint Meeting of the Congenital Heart Surgeons' Society and the European Congenital Heart Surgeons Association

Christo I. Tchervenkov, Montreal, Canada, Chairman ${ }^{1,2}$

Erle H. Austin, Louisville, United States of America ${ }^{1}$

Carl L. Backer, Chicago, United States of America ${ }^{1}$

Jeffrey P. Jacobs, St Petersburg, United States of America ${ }^{1,2}$

Bohdan Maruszewski, Warsaw, Poland ${ }^{2}$

Giovanni Stellin, Padova, Italy ${ }^{2}$

Marshall L. Jacobs, Philadelphia, United States of America ${ }^{1}$ (Ex-Officio)

${ }^{1}$ Representing the Congenital Heart Surgeons Society

${ }^{2}$ Representing the European Congenital Heart Surgeons Association
Cardiac Surgery, a meeting was held at the Sheraton Buenos Aires Hotel and Convention Center in Buenos Aires, Argentina, sponsored by the Society of Pediatric Cardiovascular Surgery "Aldo R. Castañeda”, or the Castañeda Society. This meeting was entitled "Towards a World Society:" and was attended by many more non-members than members of the Castañeda Society, including Jane Somerville from the United Kingdom. Under the chairmanship of Christo Tchervenkov, those attending the meeting reached unanimous agreement that a World Society would be established. Robert Sade has said about Aldo Castañeda "Great surgeons are distinguished from the rest of us by their intellectual brilliance and by a special creative turn of mind that leads them to innovate new technical solutions to old problems or to explore zones of human malady not previously amenable to surgery. Many are also technically skillful, and a few are administratively adept. Aldo Castañeda is a rare embodiment of all of those characteristics ...".2 Aldo Castañeda himself is completely supportive of this new World Society, and has asked for years to have his name removed from the initial society established in his honour.

Table 3. Objectives of The World Society for Pediatric and Congenital Heart Surgery

The Vision of the World Society is that every child born anywhere in the world with a congenital heart defect should have access to appropriate medical and surgical care. The Mission of the World Society is to promote the highest quality comprehensive cardiac care to all patients with pediatric and/or congenital heart disease, from the fetus to the adult, regardless of the patient's economic means, with an emphasis on excellence in education, research and community service. The vision and mission of the World Society will be pursued by working towards the following objectives:

A. Patient Care

1) To improve the quality and practice of pediatric and congenital heart surgery as a specialty across the world, with particular emphasis on areas of need through education and exchange of information

B. Education

2) To promote the professional and educational development of surgeons specializing and practicing pediatric and congenital heart surgery across the world

3) To promote the dissemination of informational support to patients, parents of patients, families of patients, and health care professionals, working in collaboration with the International Society for Nomenclature of Paediatric and Congenital Heart Disease (www.ipccc.net)

4) To develop global standards for the training and education of pediatric and congenital heart surgeons

5) To develop global standards for the practice of pediatric and congenital heart surgery across the world

6) To provide a forum for the respectful exchange of knowledge in the form of scientific meetings and publications across the world C. Research

7) To encourage basic and clinical research in pediatric and congenital heart surgery across the world with emphasis on long-term and regional outcomes

8) To organize and maintain a global database on operations and outcomes built upon extant continental databases.

D. Community Service

9) To promote the development of the World Society for Pediatric and Congenital Heart Disease, working in collaboration with pediatric and congenital cardiologists, anesthesiologists, intensivists, nurses, and all other interested physicians and allied health care professionals

10) To promote collaboration across medical and surgical subspecialties

11) To maintain an accurate database of pediatric and congenital heart surgeons and programs across the world and facilitate mentorship between surgeons and centers

12) To facilitate fundraising across the world for pediatric and congenital heart surgery in order to achieve its goals, particularly in areas of need

13) To sensitize governments and public organizations of the necessity to support and adequately fund pediatric and congenital heart surgery programs across the world

14) To interact and cooperate with existing continental organizations in the pursuit of its mission and its objectives

15) To provide professional advise to global organizations regarding issues pertaining to pediatric and congenital heart surgery 
The mission of The World Society for Pediatric and Congenital Heart Surgery is to work towards the goal that every child born anywhere in the world with a congenital heart defect should have access to appropriate medical and surgical care. The purpose of the World Society is to promote the highest quality comprehensive cardiac care to all patients with congenital heart disease, from the fetus to the adult, regardless of economic means, with an emphasis on excellence in teaching, research and community service. Detailed information about the society can be found at its website: http://www.wspchs.com/

It is a fact that many European paediatric and congenital heart surgeons are members of the European Association for Cardio-Thoracic Surgery, the European Congenital Heart Surgeons Association, and the Association for European Paediatric Cardiology. Similarly, many North American pediatric and congenital heart surgeons are members of the American Association for Thoracic Surgery, the Society of Thoracic Surgeons, and the Congenital Heart Surgeons' Society. Furthermore, the European Association for Cardio-Thoracic Surgery has very strong links with the Society of Thoracic Surgeons. A variety of other national societies exist in Japan, South America, and throughout the world. No organization currently, however, encompasses the entire planet. The rationale for the World Society, therefore, is to create a democratic forum for paediatric and congenital heart surgeons from all the continents to interact as equals in a professional society with their North American and European colleagues. This World Society will function with complete respect for, and collaboration with, all of the existing regional, national, and continental organizations. As shown in Table 3, this global collaboration has the potential to address multiple objectives. The World Society has global representation never previously seen in an organization of paediatric and congenital heart surgeons. Tables 4 and 5 list the membership of its Constitutional Council, and Governing Council or Board of Directors. The international representation and collaboration are obvious.

The long-term objective is eventually to create a World Society for Pediatric and Congenital Heart Disease. In Figures 1 and 2, we demonstrate the logical hierarchical structure and relationship between various related organizations. Our hope is that, once the surgeons organize on a global level, we will be able to expand to the World Society for Pediatric and Congenital Heart Disease, and involve cardiologists, intensivists, anaesthesiologists, and so on. In fact, the intensivists already have organized globally, having created the Pediatric Cardiac Intensive Care Society. The creation of The World Society for Pediatric and Congenital Heart Surgery, therefore, is merely another step in the process, organizing the surgical component

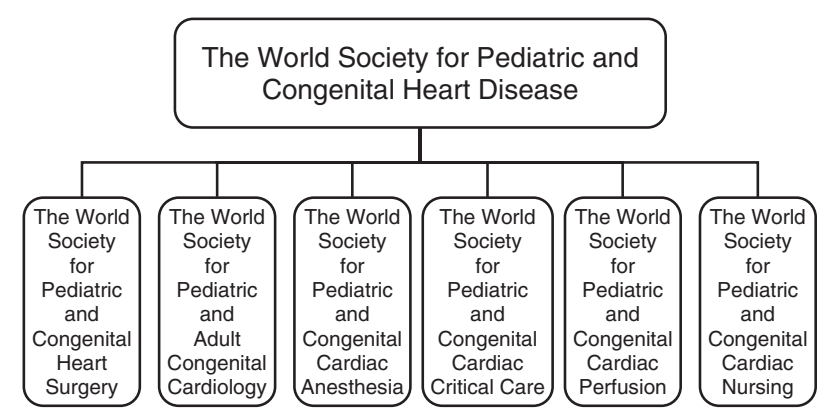

Figure 1.

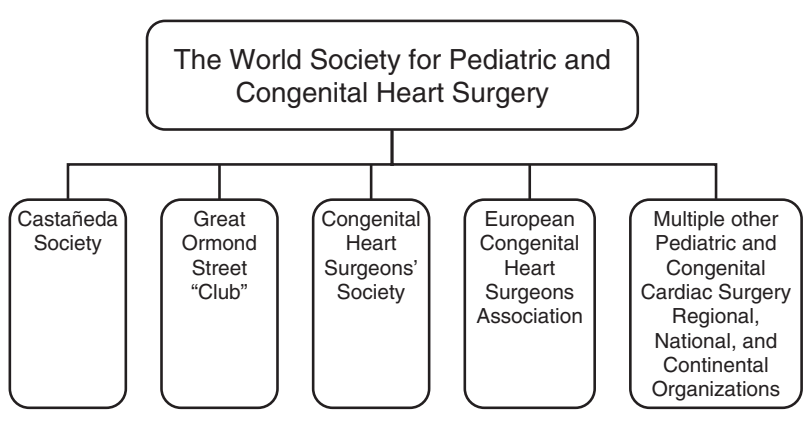

Figure 2.

of this eventual World Society for Pediatric and Congenital Heart Disease. Incredible progress has been made on a global level with the four World Congresses of Pediatric Cardiology and Cardiac Surgery that have already taken place. These sentinel meetings support the need for a new World Society of Pediatric Cardiology and Cardiac Disease. Similar successful global collaboration has been achieved with the International Society for Nomenclature of Pediatric and Congenital Heart Disease. ${ }^{3-12}$ The eventual creation of a World Society for Pediatric and Congenital Heart Disease could become an overarching infrastructure to link and complement all of these important efforts.

For now, as another step in the process, the surgeons have organized. Prior to the meeting itself, Richard and Katherine Jonas will host a dinner at their home, where initial discussions will take place to plan for the formation of The World Society for Pediatric and Congenital Heart Disease. Attendees at this organizational dinner will include many of the leaders of the various continental organizations representing pediatric and adult congenital cardiology, cardiac surgery, anaesthesia, critical care, perfusion, and nursing. As we have discussed already, the formal meeting of The World Society for Pediatric and Congenital Heart Surgery will begin on Thursday morning May 3. Aldo Castañeda will be 
Table 4. The Constitutional Council of The World Society for Pediatric and Congenital Heart Surgery

\begin{tabular}{|c|c|}
\hline $\begin{array}{l}\text { Christo I. Tchervenkov } \\
\text { (Chairman) }\end{array}$ & Montreal, Quebec, Canada \\
\hline Richard A. Jonas & $\begin{array}{l}\text { Washington DC, United } \\
\text { States of America }\end{array}$ \\
\hline Zohair Al-Halees & Riyadh, Saudi Arabia \\
\hline Christian P.R. Brizard & Melbourne, Australia \\
\hline Sertac M. Cicek & Istanbul, Turkey \\
\hline Roberto Di Donato & Rome, Italy \\
\hline Stephan Haecker & Santiago, Chile \\
\hline Vladimir Ilyin & Moscow, Russia \\
\hline Jeffrey P. Jacobs & $\begin{array}{l}\text { Saint Petersburg, Florida, } \\
\text { United States of America }\end{array}$ \\
\hline Marcelo B. Jatene & Sao Paolo, Brazil \\
\hline Yong Jin Kim & Seoul, South Korea \\
\hline Robin H. Kinsey & Johannesburg, South Africa \\
\hline Christopher J. Knott-Craig & $\begin{array}{l}\text { Birmingham, Alabama, } \\
\text { United States of America }\end{array}$ \\
\hline Christian Kreutzer & Buenos Aires, Argentina \\
\hline Hiromi Kurosawa & Tokyo, Japan \\
\hline John J. Lamberti & $\begin{array}{l}\text { San Diego, California, } \\
\text { United States of America }\end{array}$ \\
\hline Stojan Lazarov & Sofia, Bulgaria \\
\hline Juan Leon & Guatemala City, Guatemala \\
\hline Jinfen Liu & Shangai, China \\
\hline Bohdan Maruszewski & Warsaw, Poland \\
\hline Constantine Mavroudis & $\begin{array}{l}\text { Chicago, Illinois, United } \\
\text { States of America }\end{array}$ \\
\hline Dominique R. Metras & Marseilles, France \\
\hline Graham R. Nunn & Sydney, Australia \\
\hline E. Samuel Ramirez-Marroquin & Mexico City, Mexico \\
\hline Shunji Sano & Okayama, Japan \\
\hline Rajesh Sharma & Bangalore, India \\
\hline Ayman Shoeb & Cairo, Egypt \\
\hline Thomas L. Spray & $\begin{array}{l}\text { Philadelphia, Pennsylvania, } \\
\text { United States of America }\end{array}$ \\
\hline Giovanni Stellin & Padova, Italy \\
\hline Hervé Yangni-Angate & Ivory Coast, Africa \\
\hline Gerhard Ziemer & Tubingen, Germany \\
\hline
\end{tabular}

the featured guest speaker, and the meeting will be dedicated to the memory of Stella van Praagh.

We truly live in a global world, and the time has come for such a global organization. ${ }^{13,14}$ Cardiology in the Young is committed to supporting these activities, and providing a forum to facilitate exchange of ideas, and to promulgate the activities of the World Society on a regular basis. We encourage our readers to visit the web page, join the World Society, and attend the upcoming inaugural meeting.

\section{References}

1. Jacobs JP, Ungerleider RM, Tchervenkov CI, et al. Opinions from the audience response survey at the First Joint Meeting of the Congenital Heart Surgeons' Society and the European Congenital Heart Surgeons Association. Semin Thorac Cardiovasc Surg Pediatr Card Surg Annu 2005; 8: 198-217.

2. Sade RM. Aldo R. Castañeda: Apollonian surgeon. Ann Thorac Surg 1995; 60 (Suppl 6): S490-S493.
Table 5. The Governing Council (or Board of Directors) of The World Society for Pediatric and Congenital Heart Surgery

$\begin{array}{ll}\begin{array}{l}\text { Executive Committee } \\ \text { 1. President }\end{array} & \begin{array}{l}\text { Christo I. Tchervenkov, Montreal, } \\ \text { Quebec }\end{array} \\ \text { 2. 1st Vice-President } & \text { Giovanni Stellin, Padova, Italy } \\ \text { 3. 2nd Vice-President } & \text { Hiromi Kurosawa, Tokyo, Japan } \\ \text { 4. Secretary } & \text { Jeffrey P. Jacobs, St. Petersburg, } \\ & \text { Florida, United States of America } \\ \text { 5. Treasurer } & \text { Constantine Mavroudis, Chicago, } \\ & \text { Illinois, United States of America }\end{array}$

Councillors (Continental Representatives):

Africa

6. Robin H. Kinsley Johannesburg, South Africa

7. To be determined*

8. To be determined*

8. To be determined*

Asia

10. Shunji Sano

11. Jinfen Liu

12. Zohair Al-Halees

13. Rajesh Sharma

Australia and Oceania

14. Graham R. Nunn

Europe

15. Martin J. Elliott

16. Bohdan Maruszewski

17. Gerhard Ziemer

18. George E. Sarris

North America

19. Edward L. Bove

20. Richard A. Jonas

21. Thomas L. Spray

22. E. Samuel

Ramirez-Marroquin

South America

23. Marcelo B. Jatene

24. Christian Kreutzer

25. To be determined*

26. To be determined*

\author{
Okayama, Japan \\ Shangai, China \\ Riyadh, Saudi Arabia \\ Bangalore, India \\ Sydney, Australia \\ London, England \\ Warsaw, Poland \\ Tübingen, Germany \\ Athens, Greece
}

Ann Arbor, Michigan, United States of America

Washington District of Columbia, United States of America Philadelphia, Pennsylvania, United States of America Mexico City, Mexico

Sao Paulo, Brazil

Buenos Aires, Argentina
* The eventual hope of the Directors is that there will be equal representation on the Board from all continents. The remaining positions have yet to be filled.

3. Franklin RCG, Jacobs JP, Tchervenkov CI, Béland M. Report from the Executive of The International Working Group for Mapping and Coding of Nomenclatures for Paediatric and Congenital Heart Disease: Bidirectional Crossmap of the Short Lists of the European Paediatric Cardiac Code and the International Congenital Heart Surgery Nomenclature and Database Project. Cardiol Young 2002; 12 (Suppl. II): 18-22.

4. Franklin RCG, Jacobs JP, Tchervenkov CI, Béland M. European Paediatric Cardiac Code Short List crossmapped to STS/EACTS Short List with ICD-9 \& ICD-10 crossmapping. Cardiol Young 2002; 12 (Suppl. II): 23-49.

5. Franklin RCG, Jacobs JP, Tchervenkov CI, Béland M. STS/EACTS Short List mapping to European Paediatric Cardiac Code Short List with ICD-9 \& ICD-10 crossmapping. Cardiol Young 2002; 12 (Suppl. II): 50-62. 
6. Béland M, Jacobs JP, Tchervenkov CI, Franklin RCG. The International Nomenclature Project for Paediatric and Congenital Heart Disease: Report from the Executive of The International Working Group for Mapping and Coding of Nomenclatures for Paediatric and Congenital Heart Disease. Cardiol Young 2002; 12: 425-430.

7. Franklin RCG, Jacobs JP, Tchervenkov CI, Béland M. The International Nomenclature Project for Pediatric and Congenital Heart Disease: Bidirectional Crossmap of the Short Lists of the European Paediatric Cardiac Code and the International Congenital Heart Surgery Nomenclature and Database Project. Cardiol Young 2002; 12: 431-435.

8. Béland MJ, Franklin RCG, Jacobs JP, et al. Update from The International Working Group for Mapping and Coding of Nomenclatures for Paediatric and Congenital Heart Disease. Cardiol Young 2002; 14: 225-229.

9. Jacobs JP, Maruszewski B, Tchervenkov CI, et al. The current status and future directions of efforts to create a global database for the outcomes of therapy for congenital heart disease. Cardiol Young 2005; 15 (Suppl 1): 190-198.

10. Jacobs JP, Franklin RCG, Jacobs ML, et al. Classification of the functionally univentricular heart: unity from mapped codes. Cardiol Young 2006; 16 (Suppl 1): 9-21.

11. Tchervenkov CI, Jacobs JP, Weinberg PM, et al. The nomenclature, definition and classification of hypoplastic left heart syndrome. Cardiol Young 2006; 16: 339-368.

12. Jacobs JP, Franklin RCG, Wilkinson JL, et al. The nomenclature, definition and classification of discordant atrioventricular connections. Cardiol Young 2006; 16 (Suppl 3): 72-84.

13. Jacobs JP, Anderson RH. News and Comments: World Society for Pediatric and Congenital Heart Surgery Inaugural Meeting. Cardiol Young, 2007; 17: 1-2.

14. Anderson RH, Wernovsky G, Jacobs JP. News and Comments: Cardiol Young 2007; 17: in press, April. 
Table 6. Program for the Historic Inaugural Meeting of The World Society for Pediatric and Congenital Heart Surgery on Thursday May 3 and Friday May 4, 2007 in Washington DC, USA

\section{Postgraduate Course}

\section{SYMPOSIUM ON TETRALOGY OF FALLOT FROM A TO Z Dedicated to the memory of Stella Van Praagh}

\section{Local Host: \\ Programme Committee Chair Postgraduate Course Chair:}

Richard A. Jonas, MD, Washington, D.C., United States of America Sertac M. Cicek, Istanbul, Turkey

Jeffrey P. Jacobs, St. Petersburg, United States of America

Thursday May 3, 2007 - 8 a.m. to 8 p.m.

Session 1

Chairmen, Christo I. Tchervenkov and Jeffrey P. Jacobs

8:00 Welcome and Introduction of President

8:05 Presidential Welcome

8:10 Welcome from Local Host

8:15 The Stella van Praagh Memorial Lecture:

History and Anatomy of Tetralogy of Fallot

8:45 Nomenclature and Classification of Tetralogy of Fallot

9:00 Genetics of Tetralogy of Fallot

9:15 Embryology, Etiology, and Fetal evaluation

9:30 Incidence and differences around the world

$$
\text { 9:45 Break }
$$

Session 2

Chairmen, Sertac M. Cicek and Richard A. Jonas

10:15 Diagnostic evaluation: Echocardiography and the role of Catheterization

10:30 Diagnostic evaluation: Computerised Tomography and Magnetic Resonance Imaging

10:45 Intensive care and perioperative management

11:00 Anaesthesia for of Tetralogy of Fallot

11:15 Tetralogy in Developing Nations

11:30 Surgical Palliation - Indications for and types of shunts

11:45 The Conduction System in Tetralogy of Fallot

$$
\text { 12:00 Lunch }
$$

\section{Session 3}

Chairmen, Charles D. Fraser and Hiromi Kurosawa

13:00 Two stage repair of Tetralogy of Fallot

13:15 Early single stage repair of Tetralogy of Fallot

13:30 Transatrial-transpulmonary repair of Tetralogy of Fallot

13:45 Valve Sparing approach

14:00 Tetralogy with diminutive pulmonary arteries

14:15 The double outlet variant of tetralogy

14:30 Tetralogy with absent pulmonary valve

14:45 Tetralogy with aberrant coronary arteries

15:00 Tetralogy with common atrioventricular junction

15:15 Tetralogy with pulmonary atresia

15:30 Making Sense of Congenital Heart Disease within the Congenital Heart Surgeons' Society

$$
\text { 15:45 Break }
$$

Session 4

Chairmen, Zohair Al Halees and Ross Ungerleider

16:15 Late repair of Tetralogy of Fallot

16:30 Management of residual and recurrent lesions
Jeffrey P. Jacobs, Christo I. Tchervenkov Richard A. Jonas

Richard van Praagh

Marshall Jacobs

Bill Gaynor

Jim Huhta

Liu Jin Fen

Rodney Franklin

Russell Cross

Anthony Chang

Dean B. Andropoulos

Rob Kinsley

Shunji Sano

Hiromi Kurosawa

Charles D. Fraser

Richard A. Jonas

Giovanni Stellin

Constantine Mavroudis

Ed Bove

Francois Lacour-Gayet

Viktor Hraska

Christo I. Tchervenkov

Tom Karl

Frank Hanley

Ed Hickey

Rajesh Sharma

Marcelo B. Jatene 
16:45 Pathophysiology of Chronic Pulmonary Insufficiency

17:00 Repair with monocusp pulmonary valve

17:15 Pulmonary valve replacement with homografts and heterografts

17:30 Pulmonary valve replacement with the freestyle porcine aortic root

17:45 Pulmonary valve replacement with Polytetrafluoroethylene Bicuspid Valve

18:00 Pulmonary valve replacement with bovine jugular vein valved conduit

18:15 Pulmonary valve replacement with transcatheter technique

18:30 Tissue engineering of pulmonary valve

18:45 Late right ventricular failure: right ventricular remodelling surgery and cardiac transplantation

19:00 Lessons Learned form the Database of the Society of Thoracic Surgeons

19:15 Lessons Learned form the Database of the European Association of Cardiothoracic Surgeons

19:30 Late Outcome
Gerard Martin

John Brown

Joe Dearani

Kirk Kanter

James Quintessenza

George E. Sarris

Joe Martucci

John Mayer

Pedro J. del Nido

Jeffrey P. Jacobs

Bohdan Maruszewski

Bill Gaynor

Friday May 4, 2007 - 9 a.m. to 6 p.m.

Session 5

Chairmen, Christo I. Tchervenkov and Sertac M. Cicek

8:30 Welcome and Introduction of President

Sertac M. Cicek

8:35 Presidential Welcome

Christo I. Tchervenkov

8:40 Welcome from Local Host

Richard A. Jonas

8:45 Abstract 1

DEVELOPMENT OF THE PULMONARY ARTERIES AFTER THE NORWOOD PROCEDURE: COMPARISON BETWEEN BLALOCK-TAUSSIG SHUNT AND RIGHT VENTRICULARPULMONARY ARTERY CONDUIT

Joseph Caspi, MD, Timothy W. Pettitt, MD, Theodorus Mulder, MD, Aluizio Stopa, MD

Division of Cardiothoracic Surgery and Pediatric Cardiology, Louisiana State University, New Orleans, Louisiana, USA

9:00 Abstract 2

THE BIDIRECTIONAL SUPERIOR CAVOPULMONARY ANASTOMOSIS: RESULTS WITH CONTINUOUS

CARDIOPULMONARY BYPASS

Robroy Mac Iver, Robert D. Stewart, Carl L. Backer, Constantine Mavroudis

Division of Cardiovascular-Thoracic Surgery, Department of Surgery, Northwestern University Feinberg

School of Medicine, Children's Memorial Hospital, Chicago, Illinois, USA

9:15 Abstract 3

IS THE "PERFECT FONTAN" ROUTINELY ACHIEVABLE IN THE MODERN ERA?

James K. Kirklin, Robert N. Brown, Ayesha S. Bryant, Albert D. Pacifico, F. Bennett Pearce, Rob L. Romp, Edward V. Colvin, Walter H. Johnson, Yung R. Lau, William S. McMahon, Christopher J. Knott-Craig, Bhavik N. Patel, David C. Naftel

University of Alabama, Birmingham, Alabama, USA

9:30 Abstract 4

IMPROVING RESULTS OF ATRIOVENTRICULAR VALVE REPAIR IN CHALLENGING PATIENTS WITH HETEROTAXY SYNDROME

Noritaka Ota, Yoshifumi Fujimoto, Keiichi Hirose, Yuko Tosaka, Tomohiro Nakata, Yujiro Ide, Kisaburo Sakamoto

Shizuoka Children's Hospital, Shizuoka, Japan

9:45 Abstract 5

SURGICAL TREATMENT OF CONGENITAL HEART DISEASE IN ADULTS: MID-TERM RESULTS

Andrew C. Chatzis, Nicolas M. Giannopoulos, Michael Milonakis, Constantinos A.Contrafouris, Theofilos Kolettis

Chryssa Panagiotou, Prodromos Zavaropoulos, Pigi Maraki, Theofili Koussi, Joanne Sofianidou,

George V. Kirvassilis, George E. Sarris

Department of Pediatric and Congenital Heart Surgery, Onassis Cardiac Surgery Center, Athens, Greece

10:00 Abstract 6

PEDIATRIC CARDIAC ASSISTANCE IN DEVELOPING AND TRANSITIONAL COUNTRIES:

A FOURTEEN YEAR EXPERIENCE

William M. Novick, Thomas G. Di Sessa, G.L. Stidham, Tom R. Karl, Robert W. Arnold, Darko Anic, Sri O. Rao, Victor C. Baum Departments of Surgery and Pediatrics, University of Tennessee Health Sciences Center, Memphis, Tennessee, USA,

Department of Pediatrics, University of Kentucky, Lexington, Kentucky, USA; Division of Pediatric Cardiac Surgery, University of California, San Francisco, California, USA; Division of Pediatric Cardiology, Alder Hey Children's Hospital, Liverpool, UK;

Department of Cardiac Surgery, KBC-Rijeka, Croatia, Departments of Anesthesia, Pediatrics and the Cardiovascular Research Center,

University of Virginia, Charlottesville, Virginia, USA, and International Children's Heart Foundation, Memphis, Tennessee, USA

Discussant: Aubyn Marath, MD

CardioStart, Tampa, Florida, USA

10:15 Break 
Session 6

Chairmen, Giovanni Stellin and Richard A. Jonas

10:45 Abstract 7

AORTIC INSUFFICIENCY IS PROGRESSIVE AFTER THE ARTERIAL SWITCH OPERATION BUT DOES NOT NECESSARILY RESULT IN AORTIC VALVE REPLACEMENT

Rüdiger Lange, Julie Cleuziou, Jürgen Hörer, Andreas Eicken, Peter Tassani-Prell, Klaus Holper, Christian Schreiber

German Heart Center Munich at the Technical University, Munich, Germany

11:00 Abstract 8

THE ROSS-YACOUB OPERATION: A STRATEGY TO SALVAGE ANEURYSMAL AUTOGRAFT ROOTS?

Giovanni Battista Luciani, Antonia Maria Prioli, Francesca Viscardi, Francesco Santini, Giuseppe Faggian,

Alessandro Mazzucco

Divisions of Cardiac Surgery and Cardiology, University of Verona, Verona, Italy

11:15 Introduction of the President

"Bridging Cultures"

11:20 Presidential Address

"Hearts for Life Across the World"

$\begin{array}{lll}\text { 11:50 } & \text { Introduction of Honoured Guest Speaker } & \text { Richard A. Jonas } \\ \text { 12:00 } & \text { Honoured Guest Speaker } & \text { Aldo Castañeda }\end{array}$

"Pediatric Cardiac Surgery: A Challenge and Outcome Analysis of the Guatemala Effort"

Jeffrey P. Jacobs

Christo I. Tchervenkov

12:30 Lunch

Session 7

Chairmen, George Sarris and Constantine Mavroudis

13:30 Abstract 9

VASOPRESSIN LEVELS IN CHILDREN UNDERGOING CARDIOPULMONARY BYPASS

Wynne Morrison, Shari Simone, D. Conway, Jamie Tumulty, Cynthia Johnson, Marcelo Cardarelli

University of Maryland Hospital for Children, Baltimore, Maryland, USA

Discussant: David L.S. Morales, MD

Division of Congenital Heart Surgery, Texas Children's Hospital, Houston, Texas, USA

13:45 Abstract 10

EXTUBATION IN THE OPERATING ROOM AFTER NEONATAL AND INFANT CONGENITAL HEART SURGERY

David S. Cooper, Jeffrey P. Jacobs, Jean Wilhelm, Janet Kreutzer, Paul J. Chai, Harald L. Lindberg, Dien N. Vu, Jeff Miller,

Mark A. Nichter, Albert Saltiel, Arabela Stock, Michelle Smith, James A. Quintessenza

The Congenital Heart Institute of Florida (CHIF), St. Petersburg and Tampa, Florida, USA

Discussant: Alexander J.C. Mittnacht, MD

Department of Anesthesiology, The Mount Sinai Medical Center, NY, New York, USA

14:00 Abstract 11

DOES THE TRICUSPID VALVE HAVE DISPROPORTIONATE GROWTH AFTER DECOMPRESSION

OF THE RIGHT VENTRICLE IN PATIENTS WITH PULMONARY

ATRESIA AND INTACT VENTRICULAR SEPTUM?

Shu-chien Huang, MD, Kozo Ishino, MD, Shingo Kasahara, MD, Ko Yoshizumi, MD, Shunji Sano, MD

Departments of Cardiovascular Surgery and Pediatrics, Okayama University Hospital, Okayama University Graduate

School of Medicine and Dentistry, Okayama, Japan

14:15 Abstract 12

LONG-TERM RESULTS OF SURGICAL REPAIR FOR EBSTEIN'S ANOMALY: 20 YEAR EXPERIENCE

Young-Hwan Park, Sak Lee, Han-Ki Park, Chang Young Lee, Byung-Chul Chang, Bum Koo Cho

Department of Thoracic and Cardiovascular Surgery, Yonsei University College of Medicine,

Seoul, Republic of Korea

14:30 Abstract 13

SURGICAL REPAIR OF CONGENITAL MITRAL VALVE ANOMALIES IN PEDIATRIC AGE GROUP: EARLY AND MID TERM RESULTS

Giovanni Stellin ${ }^{1}$, Massimo A. Padalino ${ }^{1}$, Carlo Zebele ${ }^{1}$, Simone Speggiorin ${ }^{1}$, Alessia Cerutti ${ }^{1}$, F. Pluchinotta ${ }^{2}$, Ornella Milanesi ${ }^{1}$

Pediatric Cardiac Surgery Unit ${ }^{1}$, Pediatric Cardiology ${ }^{2}$, University of Padova Medical School, Padova, Italy 
14:45 Abstract 14

CURRENT STRATEGY OF REPAIR OF TETRALOGY OF FALLOT IN CHILDREN AND ADULTS: EMPHASIS ON A NEW TECHNIQUE TO CREATE A MONOCUSP-PATCH FOR RECONSTRUCTION OF THE RIGHT

VENTRICULAR OUTFLOW TRACT (RVOT)

Guo-Wei He, MD, PhD, DSc

Wuhan Heart Institute, The Central Hospital of Wuhan, China; Starr Academic Center, St. Vincent Heart Institute, Department of Surgery,

Oregon Health and Science University, Portland, Oregon, USA \& Department of Surgery, The Chinese University of Hong Kong, Hong Kong

15:00 Abstract 15

RESULTS OF BOVINE JUGULAR VEIN (CONTEGRA ${ }^{\circledR}$ ) USED FOR RIGHT VENTRICULAR OUTFLOW

TRACT RECONSTRUCTION

Hani K. Najm, Michael Godman, Mansour Al Mutairi

King Abdulaziz Cardiac Center, Riyadh, Saudi Arabia

15:15 Abstract 16

MID- TO LONG-TERM FOLLOW-UP OF REPAIRED AORTICO-VENTRICULAR TUNNEL

Lotfi Ben Mime ${ }^{1}$, Narayanswami Sreeram ${ }^{1}$, Stoyan Lazarov ${ }^{2}$, Georgi Christov², Gerardus Bennink

${ }^{1}$ Department of Cardiothoracic Surgery, University of Cologne, Cologne, Germany; ${ }^{2}$ National Heart Institute,

Sofia, Bulgaria

15:30 Abstract 17

THE BENEFIT OF BYPASS VERSUS INTERPOSITION GRAFT IN THE SURGICAL TREATMENT

OF COARCTATION OF THE AORTA IN IRAQ

Dr. Fadhil G.Y. AL-Amran, M.B.Ch.B, FICMS

College of Medicine, Kufa University, Baghdad, Iraq

15:45 Abstract 18

EVOLUTION OF SURGICAL MORTALITY IN CONGENITAL HEART DISEASE IN A SINGLE INSTITUTION

OF A DEVELOPING COUNTRY IN SOUTH AMERICA

Nestor Sandoval, Renato Bresciani, Juan Pablo Umaña, Javier Maldonado, Jaime Camacho, Hector Gutierrez, Claudia Jaramillo, Guillermo Palacios, Miguel Ronderos, Alberto Garcia

Department of Cardiovascular Surgery, Fundación Cardio-Infantil, Bogotá, Colombia

$$
\text { 16:00 Break }
$$

Session 8

Chairmen, Christo I. Tchervenkov and Jeffrey P. Jacobs

16:30 Business Meeting with Review and Approval of Constitution 


\section{Appendix 1: Founding Membership}

World Society for Pediatric and Congenital Heart Surgery

423 Founding Members from following 66 countries:

1. Argentina

2. Australia

3. Austria

4. Bangladesh

5. Belgium

6. Bolivia

7. Brazil

8. Bulgaria

9. Canada

10. Chile

11. China

12. Colombia

13. Côte d'ivoire

14. Czech Republic

15. Denmark

16. Egypt

17. El Salvador

18. Estonia

19. Finland

20. France

21. Georgia

22. Germany

23. Ghana

24. Greece

25. Guatemala

26. Hungary

27. India

28. Indonesia

29. Iran

30. Iraq

31. Israel

32. Italy

33. Japan
34. Korea

35. Malaysia

36. Mexico

37. Moldova

38. Morocco

39. Nepal

40. Netherlands

41. Norway

42. Oman

43. Pakistan

44. Peru

45. Philippines

46. Poland

47. Portugal

48. Qatar

49. Romania

50. Russia

51. Saudi Arabia

52. South Africa

53. Spain

54. Sudan

55. Sweden

56. Switzerland

57. Syria

58. Taiwan

59. Thailand

60. Tunisia

61. Turkey

62. Ukraine

63. United Kingdom

64. United States of America

65. Uruguay

66. Venezuela 


\section{Appendix 2: World Society for Pediatric and Congenital Heart Surgery Honorary Founding Members}

1. Robert H. Anderson

2. Eugene H. Blackstone

3. Aldo R. Castaneda

4. Denton A. Cooley

5. Mar C.R. De Leval

6. George R. Daicoff

7. Gordon K. Danielson

8. Wen Xiang Ding

9. Anthony R.C. Dobell

10. Paul A. Ebert

11. Francis M. Fontan

12. Yasuharu Imai

13. Adib D. Jatene

14. Yasunaru Kawashima

15. Guillermo O. Kreutzer

16. Yves Le Compte

17. Christopher R. Lincoln

18. Roger B.B. Mee

19. James L. Monro

20. William I. Norwood Jr

21. Lucio Parenzan

22. Claude Plan Ché

23. Donald N. Ross

24. Jane Somerville

25. Jaroslav F. Stark

26. George A. Trusler

27. Andreas E. Urban

28. Richard Van Praagh

29. John A. Waldhausen

30. William G. Williams

31. Magdi Yacoub

\author{
United Kingdom \\ USA \\ Guatemala \\ USA \\ United Kingdom \\ USA \\ USA \\ China \\ Canada \\ USA \\ France \\ Japan \\ Brazil \\ Japan \\ Argentina \\ France \\ United Kingdom \\ Australia \\ United Kingdom \\ USA \\ Italy \\ France \\ United Kingdom \\ United Kingdom \\ United Kingdom \\ Canada \\ Germany \\ USA \\ USA \\ Canada \\ United Kingdom
}




\title{
Cardiology in the Young
}

(c) 2007 Cambridge University Press

\author{
The World Society for Pediatric and Congenital Heart Surgery, \\ 3-4 May, 2007, Washington DC, United States
}

\author{
O-1 \\ Development of the pulmonary arteries after \\ the Norwood procedure: comparison between \\ Blalock-Taussig shunt and right ventricular- \\ pulmonary artery conduit \\ J. Caspi, T.W. Pettitt, T. Mulder, A. Stopa \\ Division of Cardiothoracic Surgery and Pediatric Cardiology, Louisiana \\ State University, New Orleans, Louisiana, USA \\ E-mail:CaspiJ@aol.com
}

Background: The Norwood-Sano procedure for HLHS has been associated with improved postoperative hemodynamics and outcome. To assess the effect on the development of the pulmonary arteries (PA), the size of the PA was compared between patients with a BT shunt and right ventricular-PA conduit before Bidirectional Glenn (BDG).

Methods: Between January 2000 and May 2006, 36 patients with HLHS underwent BDG. Group A $(n=19)$ had a BT shunt, $3.5 \mathrm{~mm}$ in 15 patients, and $4 \mathrm{~mm}$ in 4 . Group $\mathrm{B}(\mathrm{n}=17)$ had right ventricular-PA conduit with a $5 \mathrm{~mm}$ Gore-Tex tube. Mean age at operation was $7 \pm 1.5$ months in group $A$, and $5 \pm 1$ months in group B (NS). There was no difference in mean weight, hematocrit, arterial oxygen saturation or ventricular function between the groups. All patients had cardiac catheterization and echocardiograms prior to surgery.

Results: Total PA (Nakata) index was $192 \pm 10 \mathrm{~mm}^{2} / \mathrm{m}^{2}$ in group A, and $238 \pm 18 \mathrm{~mm}^{2} / \mathrm{m}^{2}$ in group $\mathrm{B}(\mathrm{p}=0.03)$. In group $\mathrm{B}$, the diameters of the left and right PA were comparable, whereas, in group A the left PA was smaller than the right PA $(p=0.05)$. Significant stenosis occurred at the insertion site of the BT shunt in 2 patients in group $\mathrm{A}$, and central branch stenosis was present in 1 patient in group B (NS). There were no early or late deaths. The mean PA pressure at the end of BDG was $14 \pm 2 \mathrm{mmHg}$ in group $A$ and $11 \pm 1 \mathrm{mmHg}$ in group $\mathrm{B}(\mathrm{p}=0.06)$. Persistent pleural effusion ( $>10$ days) occurred in 3 patients in group A, and 1 patient in group B (NS) Arterial oxygen saturation was higher after surgery in group B, $80 \pm 2 \%$ compared with $74 \pm 2 \%$ in group A $(\mathrm{p}=0.05)$.
Conclusions: The Norwood procedure with right ventricular-PA conduit may have favorable effects on the development of the PA due to even distribution of pulmonary blood flow.

O-2

The bidirectional superior cavopulmonary anastomosis: results with continuous cardiopulmonary bypass R. Mac Iver, R.D. Stewart, C.L. Backer, Constantine Mavroudis Division of Cardiovascular-Thoracic Surgery, Department of Surgery, Northwestern University Feinberg School of Medicine, Children's Memorial Hospital, Chicago, Illinois, USA

E-mail:c-mavroudis@nwu.edu

Objective: Some centers use deep hypothermic circulatory arrest for the bidirectional superior cavopulmonary anastomosis (SCPA). The purpose of this review was to evaluate the results of continuous cardiopulmonary bypass (CPB) with moderate hypothermia for this procedure.

Methods: Between 1989 and 2005, 114 patients (median age 0.68 years, mean age 1.58 years, range 3 months -16 years) had a unilateral $(\mathrm{n}=94)$ or bilateral $(\mathrm{n}=20)$ SCPA. All had continuous CPB with moderate $\left(32^{\circ} \mathrm{C}\right)$ hypothermia, 24 had aortic cross clamp with cardioplegia for an intracardiac procedure. Interrupted absorbable suture technique was used in 102 patients for the anastomosis.

Results: Perioperative mortality was 5\% (6/114). Mean CPB time for isolated SCPA was 94 minutes (range 44-160). Eight patients (7\%) required a graft for superior vena cava-to-pulmonary artery anastomosis. Average postoperative length of stay was 7.9 days for isolated, unilateral SCPA patients and 16.4 days for patients undergoing combined cardiac operations. Sixty-nine patients underwent later Fontan procedure (average SCPA to Fontan interval, 2.1 years). Seventy-six patients had angiograms subsequent to SCPA and there were no patients with superior vena cava/pulmonary artery stenoses.

Conclusions: The bidirectional SCPA can be performed successfully with continuous $\mathrm{CPB}$ and moderate hypothermia with a beating heart, avoiding circulatory arrest. This technique was associated with a low mortality and no late anastomotic stenosis. 
O-3

\section{Is the "perfect Fontan" routinely achievable in the} modern era?

J.K. Kirklin, R.N. Brown, A.S. Bryant, A.D. Pacifico, F.B. Pearce, R.L. Romp, E. V. Colvin, W.H. Johnson, Y.R. Lau, W.S. McMahon, C.J.

Knott-Craig, B.N. Patel, D.C. Naftel

University of Alabama, Birmingham, Alabama, USA

E-mail:ckc@uab.edu

Objective: In 1990, Fontan, Kirklin and colleagues published equations for survival after the "Perfect Fontan". After 1988, we evolved a Fontan protocol of utilizing an internal or external polytetraflouroethylene (PTFE) tube $(16-19 \mathrm{~mm}$ ) (inferior vena cava to right or left pulmonary artery) plus a bidirectional cava-pulmonary connection. The objective of this study was to test the hypothesis that "the Perfect Fontan outcome is routinely achievable in the current era utilizing a standardized surgical procedure".

Methods: Between 1/1/1988 and 12/31/2005, 112 patients underwent the Fontan procedure using an internal or external PTFE tube plus a bidirectional cava-pulmonary connection (usually as a previous procedure). This constituted $45 \%$ of the overall Fontan experience between 1988 and 1996, and 96\% of the Fontan experience between 1996 and 2005. The median duration of follow-up was 5.3 years. We calculated the expected survival for an optimal candidate ("Perfect Fontan") from the Fontan/Kirklin equations and compared this to our entire PTFE-Fontan experience (without adjustment for the standardized operation).

Results: An internal tube was utilized in 61 patients $(97 \%$ of whom were operated prior to 1998) and an external tube in 51 patients ( $95 \%$ of all Fontan operations since 1999). At 1, 5, 10 and 15 years, survival of the entire cohort receiving PTFE tubes is superimposable on the "Perfect Fontan" curve. Freedom from tube replacement/ revision was $97 \%$ at 10 years.

Conclusion: Using a standardized Fontan operation (bidirectional cava-pulmonary connection plus inferior vena cava-pulmonary artery PTFE tube connection) for nearly all single ventricle subsets, the "Perfect Fontan" early and late survival (as defined by the Fontan/Kirklin equations) is routinely achievable in the current era. The need for late tube revision/replacement is rare.

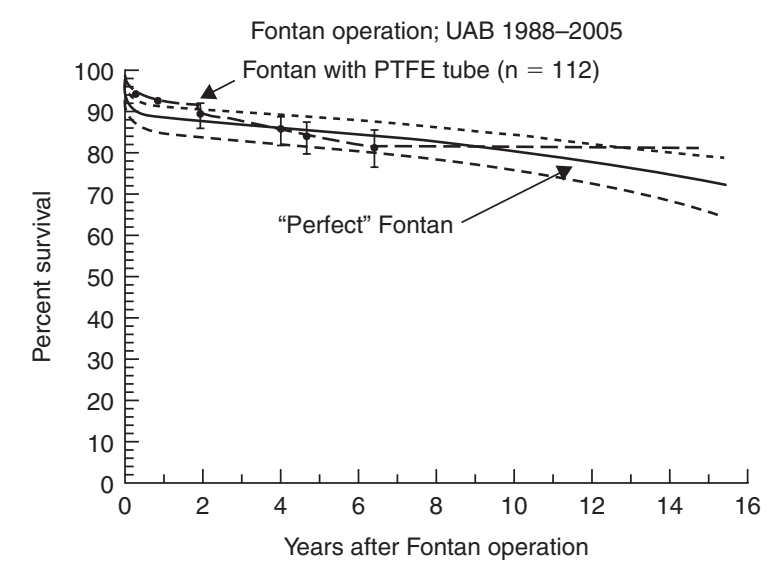

\footnotetext{
O-4

Improving results of atrioventricular valve repair in challenging patients with heterotaxy syndrome N. Ota, Y. Fujimoto, K. Hirose, Y. Tosaka, T. Nakata, Y. Ide, K. Sakamoto

Shizuoka Children's Hospital, Shizuoka, Japan

E-mail:ota@sch.pref.shizuoka.jp
}

Objective: The outlook for patients with heterotaxy Syndrome has improved over the past one decade. However, atrioventricular valve regurgitation (AVVR) remains a significant obstacle to successful staged repair. The results of atrioventricular valve (AVV) repair in this challenging patient population remains largely unknown.

Method: A retrospective review was performed on 25 patients with heterotaxy syndrome (21: right isomerism, 4: left isomerism) who had significant $(3-4+)$ AVVR necessitating AVV repair between 1994 and 2006.

Results: The median age at AVV repair was 10.1 months and median weight $6.0 \mathrm{~kg}$. Doppler/echocardiography, which was performed at one month after AVV repair, revealed 0-2+ regurgitation in 14 $(56 \%)$ and $3+$ in $11(44 \%)$. There were 5 re-repairs $(20 \%, 5 / 25)$ and 3 replacements. Patients were divided into 2 groups on the basis of AVVR at late follow-up: those with a successful late outcome $(0-2+: 17(68 \%))$ and those with a poor outcome $(3-4+: 8$ $(32 \%))$. Age and weight were not significantly different between groups. Early postoperative $0-2+$ regurgitation was not associated with a durable result $(p=0.20)$. However, successful late outcome was predictive of a good survival rate. Survival was $88.2 \%(15 / 17)$ for patients with a successful late outcome versus $12.5 \%$ (1/8) for those with a poor outcome $(\mathrm{p}=0.0007)$. Of the 15 survivors, 13 have reached to final completion, 2 Bi-directional Glenn shunt. All 15 survivors were in NYHA class I.

Conclusion: Atrioventricular valve repair can be accomplished in this challenging patient population with excellent results. Successful AVV repair at late follow-up predicts excellent late survival even if performing re-repair.

\section{O-5}

Surgical treatment of congenital heart disease in adults: mid-term results

A.C. Chatzis, N.M. Giannopoulos, M. Milonakis, C.A. Contrafouris, T. Kolettis, C. Panagiotou, P. Zavaropoulos, P. Maraki, T. Koussi, J. Sofianidou, G. V. Kirvassilis, G.E. Sarris

Department of Pediatric and Congenital Heart Surgery, Onassis Cardiac Surgery Center, Athens, Greece

E-mail:achatzis@otenet.gr

Objective: Summary of our surgical experience with the treatment of congenital heart disease (CHD) in adults.

Methods: From 9/1997-12/2006, 335 consecutive patients, aged 18-75 years with CHD presented for surgery. Principal diagnoses included atrial or ventricular septal defects in 224 patients, anomalous pulmonary venous return in 2, left heart lesions (55), right heart lesions (24), tricuspid atresia/single ventricle (4) and lesions of the thoracic arteries and veins (26). Forty-two patients (12.5\%) had 1-3 prior surgical procedure(s), while 3 were admitted as emergencies. Ten patients $(3 \%)$ had suffered prior heart related complications. Symptoms occurred in 181 patients (54\%) and 42 $(12.5 \%)$ had an established arrhythmia. Chromosomal anomalies were identified in $13(3.8 \%)$ and diagnostic catheterization was required in 199 (59\%) patients. All patients underwent complete surgical correction.

Results: There were two early deaths (0.6\%). Complications occurred in 61 patients $(18 \%)$ and included postoperative haemorrhage (8), stroke (3), pneumothorax (15), AF (22), CHB (2), endocarditis (1), wound dehiscence (1), pericardial (7) or pleural (3) effusion requiring drainage and peripheral neuropathy (1). Median ICU and hospital stay were 2 and 7 days, respectively. Two late deaths $(0.6 \%)$ occurred in patients with AF and PHT. At mean follow-up of $63 \pm 30$ months, all other patients are well with resolution or significant improvement in their symptoms. 
Conclusions: Despite the long term deleterious effects of untreated or residual/recurrent congenital heart lesions in adult patients, surgical correction can be achieved with low mortality and acceptable morbidity. Most significant complications are related to arrhythmias.

\section{O-6}

Pediatric cardiac assistance in developing and transitional countries: a fourteen year experience

W.M. Novick, T.G. Di Sessa, G.L. Stidham, T.R. Karl, R.W.Arnold, D. Anic, S. O. Rao, V.C. Baum

Departments of Surgery and Pediatrics, University of Tennessee Health

Sciences Center, Memphis, Tennessee, USA; Department of Pediatrics,

University of Kentucky, Lexington, Kentucky, USA; Division of

Pediatric Cardiac Surgery, University of California, San Francisco, California, USA; Division of Pediatric Cardiology, Alder Hey

Children's Hospital, Liverpool, UK; Department of Cardiac Surgery,

KBC-Rijeka, Croatia; Departments of Anesthesia, Pediatrics and the

Cardiovascular Research Center, University of Virginia, Charlottesville,

Virginia, USA; and International Children's Heart Foundation,

Memphis, Tennessee, USA

E-mail:ICHFNO@aol.com

Background: Pediatric cardiac services are poorly developed or totally absent in many countries around the world. Our foundation has made 140 pediatric cardiac service missions between April 1993 and March 2007 to provide cardiac services, training and education to help alleviate this problem. The purpose of this study is to present our results over this fourteen year period.

Methods: We reviewed all records relevant to the mission trips and institutional follow-up. We specifically reviewed our patient database, team lists, financial records of the foundation, inventory lists, and surgical caseload at the institutions we have assisted. The experience was divided into 3 different era's for the purpose of analysis; first and middle 5 year periods and the last 4 years.

Results: One hundred and forty trips were made in total. The distribution of the trips by region was; Central Europe 44, South America 26, Central America/Caribbean 21, Eastern Europe 16, China 13, Central/South Asia 12, Africa/Middle East 8. The number of trips per year was significantly different $(\mathrm{p}<0.001)$ between the first $(4.8 \pm 2.2)$ and second $(11.8 \pm 1.9) 5$ year periods, as well as the third interval $(14.3 \pm 2.9)$. A total of 2780 primary operations were performed.The average number of cases/year was significantly different $(\mathrm{p}<0.001)$ between the first $(86.8 \pm 33.5)$ and second $(229.2 \pm 41.3)$ periods, as well as the third $(298.3 \pm 60.9)$. Mortality was significantly different $(\mathrm{p}<0.001)$ between the first $(84.6 \%)$ and second (93.3) 5 years, and the third period (94.1\%).

Conclusions: Pediatric cardiac service assistance can improve local services. A significant commitment is required by both parties.

\section{O-7}

Aortic insufficiency is progressive after the arterial switch operation but does not necessarily result in aortic valve replacement

R. Lange, J. Cleuziou, J. Hörer, A. Eicken, P. Tassani-Prell, K. Holper, C. Schreiber

German Heart Center Munich at the Technical University,

Munich, Germany

E-mail:schreiber@dhm.mhn.de

Objectives: The arterial switch operation (ASO) is the method of choice for correction of patients with transposition of the great arteries and the Taussig-Bing heart. The long-term results are encouraging but caution is demanded in some issues like the fate of the neoaortic valve.

Methods: We reviewed our experience with the ASO over the last 20 years and could identify 419 long-term survivors. Follow-up data were collected and analyzed with a special focus on the fate of the neoaortic valve.

Results: With increasing time after ASO, an increase in the incidence of aortic insufficiency (AI) is evident. From all the surviving patients, seven required an aortic valve replacement (AVR) at a mean time of 9.8 years after ASO. One patient died 2 years after AVR. At follow-up, six patients suffer from at least moderate AI. Freedom from AVR or moderate $\mathrm{AI}$ is $100 \%, 99.1 \%$ and $97 \%$ at 5,10 and 15 years respectively. Risk factors for AVR were Taussig-Bing heart $(\mathrm{p}=0.003)$, previous operation before ASO $(\mathrm{p}=0.029)$ and postoperative AI $(\mathrm{p}<0.001)$.

Conclusions: Although aortic insufficiency is progressive after ASO, the rate of AVR is low. Especially patients with Taussig-Bing heart have a higher risk of developing AI and should remain under close follow-up.

\section{O-8}

The Ross-Yacoub operation: a strategy to salvage aneurysmal autograft roots?

G.B. Luciani, A.M. Prioli, F. Viscardi, F. Santini, G. Faggian, A. Mazzucco

Divisions of Cardiac Surgery and Cardiology, University of Verona,

Verona, Italy

E-mail:gluciani@medicina.univr.it

Background and Aim of the Study: Autograft dilatation late after the Ross procedure is leading to increase in root reoperation. In order to define feasibility and outcome of autograft valve- sparing root reoperation, a 12-year clinical experience was reviewed.

Methods: One-hundred-fifteen patients surviving an average of $6.5 \pm 1.8$ years (range $0.3-12.5$ ) after the Ross procedure underwent cross-sectional clinical and echocardiographic examination. End-points of the study were freedom from autograft dilatation $\left(\varnothing<4 \mathrm{~cm}\right.$ or $\left.0.21 \mathrm{~cm} / \mathrm{m}^{2}\right)$, from root reoperation, from root replacement and functional outcome after valve-sparing reoperation. Results: At 12 years, autograft dilatation was identified in 32 (28\%) patients, with freedom from dilatation of $48 \pm 12 \%$. In $9(8 \%)$ patients, $8 / 1 \mathrm{M} / \mathrm{F}$, this was compatible with aortic aneurysm $(<5.0 \mathrm{~cm})$. Age at Ross was $23.5 \pm 7.8$ years, diagnosis was aortic insufficiency in 6 , stenosis, in 1 , and mixed lesion, in 2; 8/9 had bicuspid aortic valve and $3(33 \%)$ prior cardiac operations. All, but one with cylinder inclusion, had undergone autograft root replacement. Risk factors for root reoperation were younger age $(p=0.04)$, prior cardiac operation $(p=0.01)$, use of root technique $(p=0.001)$. All had reoperation for autograft aneurysm at $8.5 \pm 7.9$ years after the Ross procedure. During this period, 1 additional patient operated abroad underwent root reoperation 15.2 years after Ross procedure. Two patients had root replacement and $8(80 \%)$ remodelling with autograft-valve preservation (6Yacoub operation, including 1 with bicuspid pulmonary valve; 2 sinotubular junction replacement): all survived reoperation. Severe autograft insufficiency, but not root diameter, was associated with failure to preserve the valve $(p=0.015)$. Twelve-year freedom from root reoperation was $82 \pm 6 \%$ and from full root replacement $95 \pm 2 \%$. At a mean follow-up of $2.4 \pm 1.9$ (0.4-4.5 years), after root reoperation, all pts are in NYHA class I, and 7/8 having root remodelling have mild AI or less. One patient carried out an uncomplicated pregnancy 2 years after Ross-Yacoub operation.

Conclusions: Root reoperation with pulmonary valve preservation is feasible in the majority of patients with autograft aneurysm. 
Referral of patients with dilated root for surgery prior to appearance of severe valve insufficiency increases likelihood of pulmonary valve-sparing. Early functional behaviour of remodelled autograft roots is rewarding.

\section{O-9}

Vasopressin levels in children undergoing cardiopulmonary bypass

W. Morrison, S. Simone, D. Conway, J. Tumulty, C. Johnson, M. Cardarelli

University of Maryland Hospital for Children, Baltimore,

Maryland, USA

E-mail:mcard001@umaryland.edu

Objectives: Vasopressin (AVP) in postcardiotomy shock is accepted therapy in adults, but use in children is controversial. Cardiopulmonary bypass $(\mathrm{CPB})$ is presumed to attenuate the normal intrinsic AVP response to shock. We hypothesized that AVP levels in children are altered by $\mathrm{CPB}$ and that children having low endogenous AVP levels perioperatively are more likely to develop shock or require vasopressors.

Methods: Serial AVP levels were prospectively collected from children undergoing $\mathrm{CPB}$ at a single center.

Results: Thirty-nine out of 61 eligible patients were enrolled (63\%). Median age was 5 months. Mean pre-CPB AVP level was $18.6 \mathrm{pg} / \mathrm{ml}$ (IQR 2.6-11.4). AVP levels peaked during CPB $(87.1 \mathrm{pg} / \mathrm{ml}$, IQR $30-107, p<0.00005$ vs. baseline), remained high for 12 hours $(73.5 \mathrm{pg} / \mathrm{ml}$, IQR $7.4-61, \mathrm{p}=0.002)$, were falling at 24 hours $(28.1 \mathrm{pg} / \mathrm{ml}$, IQR $5-21, \mathrm{p}=0.04)$ and reached baseline by 48 hours $(7.4 \mathrm{pg} / \mathrm{ml}$, IQR $3-12, \mathrm{p}=0.3)$. Age, gender, and surgical risk category had no influence on AVP levels. There was no statistically significant relationship between AVP levels and hypotension or vasopressor requirement. AVP level was weakly to moderately correlated with higher serum sodium $(\mathrm{r}=0.27$, $\mathrm{p}<0.00005)$ and positive fluid balance $(\mathrm{r}=0.41, \mathrm{p}<0.00005)$. Preoperative use of ACE inhibitors, preoperative congestive heart failure $(\mathrm{CHF})$ and longer $\mathrm{CPB}$ predicted higher AVP levels during the first 8 postoperative hours.

Conclusions: Children do not have deficient endogenous levels of AVP following CPB and a shock state is not associated with lower levels. Therapeutic efficacy of AVP infusion for postcardiotomy shock in children is likely due to mechanisms other than plasmatic level stabilization.

\section{O-10 \\ Extubation in the operating room after neonatal and infant congenital heart surgery \\ D.S. Cooper, J.P. Jacobs, J. Wilhelm, J. Kreutzer, P.J. Chai, H.L. Lindberg, D. N. Vu, J. Miller, M.A. Nichter, A. Saltiel, A. Stock, M. Smith, J.A. Quintessenza \\ The Congenital Heart Institute of Florida (CHIF), St. Petersburg and Tampa, Florida, USA \\ E-mail:davidscooper@verizon.net}

Background: Potential advantages of early extubation include decreases in ventilator-associated nosocomial infections and use of sedative medications, shorter ICU and hospital stay, and decreased cost. We adopted an aggressive strategy to avoid unnecessary mechanical ventilation that employed extubation in the operating room in selected infants and neonates after open heart surgery. We review our experience.
Methods: A retrospective chart review was performed of all infants ( $\leqslant 365$ days) who underwent open heart surgery from January 2002 to December 2006 at The Congenital Heart Institute of Florida (CHIF). Two subgroups were analyzed:

1) AllVSD, AVSD, TOF repair, and Glenn,

2) Neonates ( $\leqslant 31$ days).

Results: In the 5 years reviewed, CHIF performed 3971 cardiothoracic operations, 2293 in infants, 1029 infant open heart operations, and 374 neonatal open heart operations.

433/1029 infant operations were in subgroup 1: VSD (17\%), AVSD (20\%), TOF (40\%), Glenn (23\%). 263 of the 433 patients (61\%) were extubated in the operating room with only $4(1.5 \%)$ requiring re-intubation. For these subgroup 1 infants, operative mortality was $1 \%$ if extubated in the operating theater and $6 \%$ if not.

In subgroup 2, 13/274 (3.5\%) of neonates undergoing open heart surgery were extubated in the operating room with one requiring re-intubation: TGA/IVS (3), TGA/VSD (2), BT shunt (2), Aoarch hypoplasia/VSD (2), IAA/VSD (1), TOF (1), Truncus (1), AVSD (1).

Conclusions: Extubation in the OR after open heart surgery in infants and neonates can be done safely with appropriate patient selection. Further study will help elucidate criteria for application of this strategy.

\section{O-11}

Does the tricuspid valve have disproportionate growth after decompression of the right ventricle in patients with pulmonary atresia and intact ventricular septum? S.-C. Huang, K. Ishino, S. Kasahara, K. Yoshizumi, S. Sano Departments of Cardiovascular Surgery and Pediatrics, Okayama University Hospital, Okayama University Graduate School of Medicine and Dentistry, Okayama, Japan

E-mail:dtsurg99@yahoo.com.tw

Objective: Tricuspid valve (TV) size is the major determinant of outcomes in pulmonary atresia with intact ventricular septum (PAIVS). Lack of right ventricle (RV)-pulmonary artery (PA) continuity is associated with poor TV growth (decrement in Zvalue). However, most reports did not show the evidence for the disproportionate growth of the tricuspid valve after establishment of RV-PA continuity.

Methods: Forty patients with PA-IVS and received initial RV decompression procedure (surgical valvotomy, $\mathrm{n}=38$, balloon valvotomy $\mathrm{n}=1, \mathrm{RV}$ outflow patch, $\mathrm{n}=1$ ) for planned staged repair in our institute were reviewed. The $\mathrm{Z}$-value of tricuspid valve was obtained from the echocardiography-derived normal value. The late $\mathrm{Z}$-value $\left(\mathrm{Z}_{\mathrm{t} 2}\right)$ was measured before definitive repair, or the last available data if definitive repair was not reached yet. The data were compared with initial $Z$-value $\left(Z_{t 1}\right)$ and the factors associated with the change of $Z$-value $\left(Z_{t 2}-Z_{t 1}\right)$ were analyzed. Results: The initial tricuspid $Z$-value $\left(Z_{t 1}\right)$ was $-6.2 \pm 3.5$, After treatment $\left(Z_{\mathrm{t} 2}\right)$, the $Z$-value was $-6.0 \pm 3.4(\mathrm{n}=34)$. Overall the tricuspid $Z$-values were not changed $(p=N S$ by paired $t$-test $)$. Individually, the change of $\mathrm{Z}$ value $\left(\mathrm{Z}_{\mathrm{t} 2}-\mathrm{Z}_{\mathrm{t} 1}\right)$ was larger than +2 in $11(32.4 \%)$ patients, and smaller than -2 in $6(17.6 \%)$ patients. The increase of $\mathrm{Z}$ value $\left(\mathrm{Z}_{\mathrm{t} 2}-\mathrm{Z}_{\mathrm{t} 1}\right)$ was not related to the age of initial operation, presence of sinusoid communication, and severity of tricuspid regurgitation, but was significantly associated with RV pressure/LV pressure measured after initial palliation $(\mathrm{r}=-0.54, \mathrm{p}=0.001)$, and the initial tricuspid valve $Z$-value $\left(Z_{t 1}\right)(r=-0.40, p=0.02)$.

Conclusions: The lower RV pressure after initial procedure and small initial TV Z-value were associated with better TV growth. 
Whether this finding changes the destiny by "initial" Z-value remain to be seen.

\author{
O-12 \\ Long-term results of surgical repair for Ebstein's \\ anomaly: 20 year experience \\ Y.-H. Park, S. Lee, H.-K. Park, C.Y. Lee, \\ B.-C. Chang, B.K. Cho \\ Department of Thoracic and Cardiovascular Surgery, Yonsei University \\ College of Medicine, Seoul, Republic of Korea \\ E-mail:hank@yumc.yonsei.ac.kr
}

Background: We retrospectively evaluated clinical results of surgical management for Ebstein's anomaly.

Material and Methods: Between February 1984 and June 2006, fifty patients underwent surgical treatment for Ebstein's anomaly. Mean age was 26.9 years, and 19 patients were male. Associated anomalies included atrial septal defect (33), patent ductus arteriosus (2), ventricular septal defect (1), and pulmonary stenosis (4), and $90 \%$ $(45 / 50)$ of patients had more than moderate degrees of tricuspid regurgitation. Carpentier type A was present in 6 patients, type B in 26, type $\mathrm{C}$ in 14, and type $\mathrm{D}$ in 4 . Ten patients were associated with WPW syndrome. Conservative surgery was possible in 31 patients (tricuspid annuloplasty, plication of atrialized right ventricle), Fontan operation was performed in 4 patients, tricuspid valve replacement in 12, and palliative surgery in 2 patients. 13 patients were associated with bi-directional cavopulmonary shunt (BCPS; one and a half ventricular repair), and 10 patients with WPW syndrome, and 4 patients with atrial fibrillation underwent concomitant ablation.

Results: Postoperative mean NYHA functional class $(2.6 \rightarrow 1.4)$ and cardio-thoracic ratio $(0.65 \rightarrow 0.59)$ were decreased significantly $(\mathrm{p}<0.001, \quad \mathrm{p}=0.014)$. Mean oxygen saturation $(86.6 \rightarrow 94.1 \%)$, and TR grade $(3.54 \rightarrow 1.50)$ were also significantly improved $(\mathrm{p}=0.004, \mathrm{p}<0.001)$. For comparison of BCPS, and conservative surgery, preoperative right ventricular pressure $(33.0$ vs. $41.3 \mathrm{mmHg}$ ), ICU stay (2.86 vs. 1.89 days), hospital say (10.6 vs. 16.8 days), and left ventricular ejection fraction (64.3 vs. $72.8 \%)$ were statistically different. Postoperative mortality occurred in 3 patients $(6 \%)$ due to biventricular failure in 2 patients, and sepsis in the other patient. Mean follow up duration was 101.5 months, and one patient died of Fontan failure and 6 patients required reoperation (bioprosthetic degenerative change (2), Fontan conversion (4)). Overall survival rate at 20 years was $90.2 \%$, freedom from reoperation rate, and cardiac related event were $78.9 \%$, and $49.2 \%$, respectively.

Conclusion: Surgical management of Ebstein's anomaly can be performed safely, and associated BCPS may be helpful in high-risk patients. Adequate application of surgical management may increase long-term survival with reduction of reoperation.

\section{O-13}

Surgical repair of congenital mitral valve anomalies in pediatric age group: early and mid term results G. Stellin ${ }^{1}$, M.A. Padalino ${ }^{1}$, C. Zebele ${ }^{1}$, S. Speggiorin ${ }^{1}$, A Cerutti $^{1}$, F. Pluchinotta ${ }^{2}$, O. Milanesi ${ }^{1}$

Pediatric Cardiac Surgery Unit ${ }^{1}$, Pediatric Cardiology ${ }^{2}$, University of Padova Medical School, Padova, Italy

E-mail:massimo.padalino@unipd.it

Objective: To evaluate the effectiveness of mitral valve (MV) repair in patients with congenital MV dysplasia, with or without associated cardiac malformations.
Methods: Between January 1987 and December 2005, 60 patients underwent $M V$ repair $(M / F=28 / 32$, median age 3.9 years, range 1.8 month -19.8 years). AV septal defect and univentricular heart were excluded from this analysis. Patients were divided in: Group A (MV anomaly was the main cardiac defect, 26), Group B(MV anomaly was associated to major intracardiac lesions, 34). Prevalent dysfunction was regurgitation in $35(58.3 \%, 18 / 26$ in Group A, $17 / 34$ in Group B), stenosis in 25 (41.7\%, 8/26 in Group A, $17 / 34$ in Group B). Surgical repair was tailored to patient's MV anatomy. Outcome for mortality, late reoperations and clinical follow up were analysed.

Results: Mitral valve reconstruction was possible in all. There were 2 early deaths (3\%, in Group B, 2/34, related to preoperative LV dysfunction). At a mean follow up of 8.1 years (median 7.7 years, range 1 months -18.6 years) there were 2 late deaths (one for each group). Residual MV regurgitation was less than moderate in $44 \mathrm{pts}$ $(78 \%)$, while mild MV stenosis was detected in $6(10 \%)$. In the entire sample, in Groups A and B, respectively, freedom from mitral valve replacement was 76,88 and $73 \%$, overall survival was 92,95 and $90 \%$ at 18.6 years.

Conclusions: Surgical repair for congenital MV anomalies is an effective and safe procedure, which has a favourable functional outcome in the medium and long term, even in the most severe forms.

\section{O-14}

Current strategy of repair of tetralogy of Fallot in children and adults: emphasis on a new technique to create a monocusp-patch for reconstruction

of the right ventricular outflow tract

G. $-W . H e$

Wuhan Heart Institute, The Central Hospital of Wuhan, China; Starr Academic Center, St.Vincent Heart Institute, Department of Surgery, Oregon Health and Science University, Portland, Oregon, USA $\&$ Department of Surgery, The Chinese University of Hong Kong, Hong Kong

E-mail:monicawan@surgery.cuhk.edu.hk

Objectives: Strategies of repair of Tetralogy of Fallot (TOF) change with the age of patients. In older children ( $<4$ years) and adults, the strategy may be composed of lower rate and different method of reconstruction of RVOT to maximally avoid or reduce pulmonary insufficiency (PI) that may compromise the right ventricular (RV) function. This study tests the hypothesis that in repair of TOF in children and adults the repair could be fulfilled with low rate of transannular patch-repair (TAPR) and a new technique to create a mono-cusp valved patch if TAPR is necessary.

Methods: From 2001 through 2005, 74 patients (50 male, 24 female; mean age of 13.6 years \pm 0.8 years, ranging from 4 to 34 years) with typical clinical features and pathology of TOF (67) or double outlet RV (DORV)-type-TOF (7) underwent complete repair. The operation was performed under moderate hypothermia $\left(26^{\circ}-28^{\circ} \mathrm{C}\right)$ and blood cardioplegia. The VSD was repaired. The resection of RVOT stenosis \pm pulmonary valvotomy was principally through RA unless a RVOT/pulmonary artery (PA) incision was necessary. A new two-patch technique to create a folded mono-cusp valve by using autologous pericardium was applied since August, 2004.

Results: The repair was completely through RA in 52 and through $\mathrm{RA}+\mathrm{RVOT} / \mathrm{PA}$ in 22 (18/4).TAPR was performed in 17 patients (23\%, 8 non-valved and 9 valved). The aortic cross-clamp time was $130.1 \pm 6.8 \mathrm{~min}$ in TAPR group and $85.8 \pm 4.6 \mathrm{~min}$ in nonTAPR group $(\mathrm{p}<0.0001)$. The operative mortality was $4.0 \%$ $(3 / 74)$ in all, $2.9 \%(2 / 67)$ in TOF patients and was similar in TAPR and non-TAPR $(\mathrm{p}=0.11)$. The monocusp-patch repaired patients 
had minimal PI and good RV function postoperatively and at the 8 12-month follow-up.

Conclusions: The current strategy of repair of TOF in older children and adults should include the low rate of TAPR of RVOT that should be indicated only in patients with absolutely small pulmonary annulus. If indicated, the new folded monocusp-patch technique is an effective and simple way to eliminate postoperative PI with no additional cost.

\section{O-15 \\ Results of bovine jugular vein (contegra ${ }^{\circledR}$ ) used for right ventricular outflow tract reconstruction \\ H.K. Najm, M. Godman, M.A. Mutairi \\ King Abdulaziz Cardiac Center, Riyadh, Saudi Arabia \\ E-mail:haninajm@hotmail.com}

Objectives: In search for the perfect conduit for right ventricle to pulmonary artery reconstruction, we evaluated the surgical and echocardiographic results of a bovine jugular vein conduit $\left(\right.$ contegra $\left.^{\circledR}\right)$.

Methods: Between October 2000 and April 2005,70 conduits were implanted at a median age of 10 months. Indication for implantation was, absent connection in 50, stenotic connection in 13 , and used to replace pulmonary autograft in 7 . Mean conduit diameter was $15 \mathrm{~mm}$. All children were evaluated by echocardiography immediately after repair and at regular intervals postoperatively.

Results: There was one early death (2\%). Clinical follow up is up to 5 years (mean 30 months) and echocardiographic follow up is up to 45 months (mean 25 months). During the follow-up there were two late mortalities. Latest echocardiographic follow up revealed none or mild pulmonary regurgitation (PR) in $79 \%$, moderate PR in $19 \%$, and severe PR in $2 \%$. The valve leaflet function was seen to be normal in 65\%. Mild conduit stenosis seen in 5 . Bilateral branch stenosis was seen in 5 children, three of which have been explanted and one was stented. During follow up transient clot formation on one leaflet was seen resolving spontaneously. Unique features of this conduit include, flow reversal in the conduit with no significant PR, reduced or absent leaflet motion identified early improves at follow-up.

Conclusions: Results of the contegra ${ }^{\circledR}$ in reconstruction of the right ventricular outflow tract are good. Echocardiographic characteristics are unique. The need for anticoagulation may become necessary.

\section{O-16}

Mid- to long-term follow-up of repaired aorticoventricular tunnel

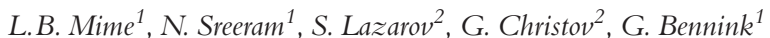

${ }^{1}$ Department of Cardiothoracic Surgery, University of Cologne, Cologne, Germany, ${ }^{2}$ National Heart Institute, Sofia, Bulgaria

E-mail:gerardus.bennink@uk-koeln.de

Objective: Although an exceedingly rare congenital anomaly an aortico-ventricular tunnel (AVT) is always present at birth and is likely to be symptomatic in the first year of life. In this retrospective study we describe our common results and follow-up of 9 patients with AVT.

Methods: Nine patients of 2 institutions were reviewed prior and after correction of AVT using operation notes, patients charts and echocardiographic follow-up data.

Results: In all except 2 patients the diagnosis was made directly after birth and operated in the first 6 months of life. The remaining two patients were operated at 2 and 14 years respectively. All patients demonstrated signs and symptoms of congestive heart failure, moderate to severe LV dilation and reduced ejection fraction prior to their operation. Two earlier patients died, one due to recanalisation and the concurrent reoperation, the other one due to late diagnosis and persistent LV dysfunction despite the usage of ECMO. The remaining 7 survivors demonstrated during their follow-up of up to 16 years all normalized to mildly dilated $\mathrm{LV}$ with only mild or moderate depression of ejection fraction. The aortic regurgitation in this small group ranged from 0 to 2 .

Conclusions: Although a small subset of patients, this rare anomaly can be corrected with an acceptable risk, whereas later diagnosis and complications after the operation increase the peri- and postoperative risk. Follow-up shows a general improvement of LV function, whereas, aortic valve pathology has to be closely watched in the near future.

\section{O-17}

The benefit of bypass versus interposition graft in the surgical treatment of coarctation of the aorta in Iraq F.G.Y.Al-Amran College of Medicine, Kufa University, Baghdad, Iraq E-mail:fadhilyousif@hotmail.com

A total no. of 48 cases of coarctation of aorta with average age of $20 \pm 7$ years during the period (1998 to 2005), 56\% of them underwent interposition surgery for the coarct segment, either interposition graft or resection; manipulation and reapproximation those patients represent the first group. The second group represents $44 \%$, sustained bypass graft from the junction of subclavian artery with the aorta to the distal point beyond the coarct segment.

The influence of 52 preoperative, intraoperative and postoperative characteristics on operative mortality and morbidity risk was investigated utilizing stepwise logistic regression analysis.

The overall operative mortality was two deaths both in the first group only with no mortality in the second group.

The use of first group surgical approach, long aortic clamping time (which is consistent with the first group) and high left ventricular mass index; all were strong predictors of operative mortality, while operative morbidity (which includes spinal cord insult, sustained postoperative hypertension, and cerebrovascular accident) was strongly predicted by using first surgical approaches while moderately predicted by high left ventricular mass index and increasing age. Thus, the early results of coractation of aorta surgery can be related to several specific variables describing the surgical approaches of the patients. This information should provide for a more rational approach to this surgical procedure, at least in terms of early risk/benefit deliberations; the surgeon must identify the factors that predict postoperative morbidity and mortality to develop alternative strategies for high risk patients.

\section{O-18}

Evolution of surgical mortality in congenital heart disease in a single institution of a developing country in South America

N. Sandoval, R. Bresciani, J.P. Umaña, J. Maldonado,

J. Camacho, H. Gutierrez, C. Jaramillo, G. Palacios,

M. Ronderos, A. Garcia

Department of Cardiovascular Surgery, Fundación Cardio-Infantil,

Bogotá, Colombia

E-mail:nestorsandoval@cable.net.co 
Background: Surgical mortality has been internationally used as an indicator of effectiveness in pediatric cardiac surgery in order to compare results between institutions and to develop the program by itself. These results ultimately recognize an institution as a surgical reference center.

Materials and Methods: From January 2001 to December 2006, 2.675 patients were operated at the Fundación Cardio-Infantil, Bogota, Colombia. Patients were divided in two groups: Group 1, from 2001 to 2003 and Group 2, from 2004 to 2006. We analyzed the surgical mortality by category risk RACHS-1 and the surgical mortality between the groups.

Results: There were 1,437 patients in Group 1 and 1,238 in Group 2. Total mortality decreased from $8.8 \%$ in Group 1 , to $7.2 \%$ in Group $2(\mathrm{p}<0.001)$. We found a decrease in patients in category $1(p<0.001)$, stability in category $2(p=0.59)$, increase in category $3(\mathrm{p}=0.001)$ and increase in category $4(\mathrm{p}=0.037)$. Mortality in categories 1, 2, 3 showed a significant statistical decrease $(p=0.001)$. In category 4 , although there was a smaller mortality, this was not statistically significant.

Conclusion: Although these results can not be compared with developed countries, the actual mortality in our Hospital shows a significant permanent decrease in all categories even though the number of higher risk patients has increased each year. We need a more accurate classification of patients in order to compare variables related to the admission characteristics of our very deprived population.

P-1

Outcome following surgical correction of tetralogy of Fallot in a newly created pediatric cardiac surgery unit M.R. Adrianzén, M. Arboleda, I.N. de Guzmán, A. Abarca,

L. Collantes, P.P. de León, M. Cabanillas

Department of Pediatric Cardiology and Pediatric Cardiac Surgery,

National Heart Institute, EsSalud, Peru

E-mail:manueladrianzen@viabcp.com

Background: This study was undertaken to assess the follow up and identify risk factors for early mortality following complete repair of tetralogy of Fallot in a newly created Pediatric Cardiac Surgery Unit started six years ago.

Methods and Results: Between May 2000 and Dec 2006,113 patients with tetralogy of Fallot underwent a complete surgical correction at a newly created single institution. The medium values for age and weight were 730 days and $11.45 \mathrm{~kg}$ respectively. The medium values for ICU time and time of hospitalization were 3 and 16.3 days respectively. The overall mortality was $8.8 \%(\mathrm{n}=95)$. Multivariate analysis showed age less than 180 days $(p=0.038$ ), weight less than $10 \mathrm{~kg}(\mathrm{p}=0.004)$ and time of cardiopulmonary support more than 120 minutes ( $p=0.006$ ), as independent risk factors for early mortality. Type of repair with transannular patch or valved conduit, was not a significant risk factor in this series. The Kaplan-Meier survival analysis showed a cumulative survival of $90.79 \%$ with a medium follow up of 2 years.

Conclusions: Patient-related and predetermined operative variables have a major influence on the early outcome following complete repair of tetralogy of Fallot.

\section{P-2}

Individualized approach to the initial treatment of pulmonary atresia and ventricular septal defect A.F.Ahmed, K. Zahka, E. Siwik, F. Erenberg, Y. Al-Khatib, A. Golden, M. Karimi, M. Uddin, J. Stork, H. Hennein

Rainbow Babies and Children's Hospital, Case Western Reserve

University, Cleveland, Ohio, USA

E-mail:FaroukAhmed@case.edu
Background: Pulmonary atresia with ventricular septal defect (VSD) is characterized by diverse sources of pulmonary blood supply and morphological differences limiting a unified approach to this heterogeneous disease. We have adopted an individualized approach for the management of pulmonary atresia with VSD, which combines surgery with interventional procedures.

Methods: Between 1993 and 2003, 66 consecutive patients underwent an individualized approach for the management of their pulmonary atresia with VSD. Patients were grouped according to pulmonary arteries (PAs) morphology, Nakata index and major aorto-pulmonary collaterals (MAPCAs) into three groups. In group A (29 patients), 18 had a single stage repair with VSD closure and right ventricular outflow (RVOT) reconstruction via transannular patch (TAP) and 11 patients via right ventricle (RV) to PAs conduit. Group B (9 patients) 7 initially underwent modified Blalock-Taussig shunt (MBTS) and 2 underwent TAP. This was followed by complete repair in 5 patients. In group C (28 patients), 21 underwent RVOT conduit, MBTS in 6, and aortopulmonary shunt in one. This was followed by unifocalization of MAPCAs in both lungs with VSD closure in 20 patients, and catheter-based interventions in 8 . This was then followed by complete repair in 24 patients.

Results: The number of procedures per patient before complete repair was $0,1.2 \pm 0.1$, and $3.8 \pm 1.3$ for groups $\mathrm{A}, \mathrm{B}$, and $\mathrm{C}$ respectively. The post-repair right ventricular to left ventricular pressure ratio was $0.42 \pm 0.09$ for group A, $0.38 \pm 0.27$ for group $\mathrm{B}$, and $0.52 \pm 0.14$ for group C. Kaplan-Meier 10-year freedom from reoperation was $46 \%, 0 \%$, and $0 \%$ for groups A, B, and C respectively. Kaplan-Meier 10-year freedom from mortality was $96.43 \%, 100 \%$, and $96.55 \%$ for groups A, B, and C respectively. Conclusions: Excellent results can be achieved in the current era through an individualized approach for the management of pulmonary atresia with VSD. The initial procedure is determined by PAs morphology, Nakata index and MAPCAs. A combined surgical \& interventional approach is used to restore central PAs circulation which then can be followed by complete repair.

\section{P-3}

Short- and long-term results of coarctation repair A. Böning ${ }^{1}$, M. Schwarz ${ }^{1}$, G. Lutter ${ }^{1}$, T.Attmann ${ }^{1}$, G. Fischer ${ }^{2}$, J. Cremer ${ }^{1}$, J. Scheewe ${ }^{1}$

Departments of ${ }^{1}$ Cardiovascular Surgery and ${ }^{2}$ Pediatric Cardiology,

University Hospital Schleswig-Holstein, Campus Kiel, Kiel,

Germany

E-mail:aboening@uksh-kiel.de

Objective: After coarctation repair in early infancy, the return of a significant gradient in the aortic isthmus may occur in up to $20 \%$ of the patients. We tried to determine risk factors for re-coarcation in our patients.

Patients and Methods: Between 01/1995 and 12/2005, 199 coarctation repairs (15 with ECC due to concomitant procedures) were performed at our institution. Two of the 199 patients (median age 42 days, median weight $4.1 \mathrm{~kg}$, mean gradient $45 \pm 18 \mathrm{mmHg}$ ) had an interrupted aortic arch, 107 had aortic arch hypoplasia. The most common concomitant diagnoses were PDA ( $\mathrm{n}=80)$, VSD $(\mathrm{n}=68)$, ASD $(\mathrm{n}=64)$, PFO $(\mathrm{n}=49)$.

The 123 end-to-end and the 65 end-to-side aortic anastomoses were performed using a single continuous suture, 18 patients received a subclavian patch augmented anastomosis, in 6 patients, a vascular prosthesis was applied.

Results: The gradient over the aortic arch could be reduced to $2 \mathrm{mmHg}$ (median) intraoperatively and to $12 \pm 8 \mathrm{mmHg}$ 
(postoperative echo). Early mortality was $2 \%(\mathrm{n}=4)$ and late mortality $2 \%(\mathrm{n}=4)$. During the follow-up time, four patients $(2.0 \%)$ had repeat coarctation surgery, 17 patients $(8.5 \%)$ a balloon dilatation/stenting of the coarctation, and 3 patients $(1.5 \%)$ had both. There were no significant differences between the successfully operated and the repeat surgery group regarding weight, age, intra- and postoperative gradient, incidence of hypoplastic aortic arch, and anastomosis technique.

Conclusions: Coarctation surgery can be done with a low perioperative risk even in small neonates and emergencies. In the long term, there is still a significant proportion of re-coarctations, for which we were not able to identify particular risk factors.

P-4

Dexmedetomidine use in a pediatric cardiac intensive care unit: can we safely use it in infants after cardiac surgery?

C. Chrysostomou, T. Avolio, R. Orr, D. Berry, V. Morell, R. Munoz

University of Pittsburgh School of Medicine, Pittsburgh, Pennsylvania, USA

E-mail: Constantinos.Chrysostomou@chp.edu

Objective: To evaluate safety and efficacy of dexmedetomidine in spontaneously breathing and intubated infants admitted to the cardiac ICU.

Methods: We analyze the data from 43 infants receiving dexmedetomidine after cardiac surgery.

Results: Forty-three infants, age $4.3 \pm 3.2$ (0.2-11 months) with weight $5.5 \pm 1.8(1.8-8.8 \mathrm{~kg})$ were included. Table 1 shows the surgical procedures performed. 22 patients (51\%) were already intubated at the initiation of dexmedetomidine. In 2 , where dexmedetomidine was initiated in anticipation for extubation, later proved unsuitable for extubation and dexmedetomidine was discontinued. All remaining 20 patients were subsequently extubated. Five patients with chronic problems, residual defects and prolonged intubation times were reintubated. Twenty-one patients $(49 \%)$ were spontaneously breathing at the initiation of the dexmedetomidine and remained spontaneously breathing throughout. Respiratory rate was $31.01 \pm 12.39$. Dexmedetomidine dose was $0.54 \pm 0.19$ $\mathrm{mcg} / \mathrm{kg} / \mathrm{hr}(0.1-1.25 \mathrm{mcg} / \mathrm{kg} / \mathrm{hr})$ and duration was $24 \pm 15$ hours (3-72). Ten patients (23\%) received $0.5-1 \mathrm{mcg} / \mathrm{kg}$ bolus. $4.8 \pm 4.3$ $(0-17)$ rescue, sedative boluses per patient were given. Fentanyl, chloral hydrate, and morphine were the most common. Three patients $(7 \%)$ received no rescue sedation. Sedation score was $1.24 \pm 0.75$ (mildly sedated) and pain score was $1.74 \pm 1.50$ (mild pain). SBP and HR decreased from baseline but there was no significant hypotension or bradycardia. Mean SBP was $85 \pm 16$ and HR $128 \pm 18$. In 2 patients, dexmedetomidine was electively discontinued after 8 and 11 hours of infusion. First patient while on nitroprusside, SBP decreased after hydralazine was given. Second patient, 2 month old, HR had decreased from the 110s to 90s. Six had arrhythmias prior to dexmedetomidine. Two had junctional ectopic tachycardia, 1 junctional accelerated rhythm and 3 first or second degree heart block. Four were temporarily paced. All recovered to sinus rhythm. Thirteen patients (30\%) were fed without any significant abdominal symptoms. There were no mortalities.

Conclusions: Dexmedetomidine was used in infants after cardiac surgery for up to 72 hours and proved to be efficacious in both intubated and spontaneously breathing patients without major cardiorespiratory or other side effects.
Table 1.

\begin{tabular}{lcc}
\hline & $\mathbf{n}$ & $\mathbf{\%}$ \\
\hline Tet & 11 & 25.6 \\
CoA & 6 & 14 \\
Glenn & 5 & 11.6 \\
VSD & 3 & 7 \\
AVSD & 3 & 7 \\
ASD \& VSD & 2 & 4.7 \\
Pulm valvotom \& VSD & 2 & 4.7 \\
d-TGA & 1 & 2.3 \\
AP window & 1 & 2.3 \\
CoA \& VSD & 1 & 2.3 \\
RV-PA conduit & 1 & 2.3 \\
BT shunt & 1 & 2.3 \\
LPA augmentation & 1 & 2.3 \\
Hypoplastic Ao Arch \&VSD & 1 & 2.3 \\
Other & 4 & 9.3 \\
Total & 43 & 100 \\
\hline
\end{tabular}

\section{P-5}

Staged Norwood palliation in hypoplastic left heart syndrome

E.M.D.Walter, A. Loforte, M. Huebler, V.Alexi-Meskishvili, R. Hetzer

Department of Cardiovascular and Thoracic Surgery, Deutsches

Herzzentrum Berlin, Berlin, Germany

E-mail:delmo-walter@DHZB.de

Objective: Surgical options for infants with HLHS are either cardiac transplantation or Norwood palliation, followed by the 2stage Fontan procedure. We describe our 17-year experience with staged surgical management of HLHS.

Patients and Methods: Between 12/1989 and 09/2006, 64 patients (38 males) with classical HLHS underwent Norwood procedure (mean age $11.8 \pm 2.5$, range $0-118$ days). Mean weight at operation was 3.4 (range $2.1-4.3$ ) kg. Subsequently 21 patients underwent bidirectional Glenn procedure (stage II) and 11 modified Fontan procedure (stage III). Others are awaiting stage II and/or III. Follow-up was 143.2 patient/years (mean $2.3 \pm 0.45$, range $0-14$ years).

Results: Including the learning curve, overall early mortality in 1989-1999 after the Norwood procedure was 39.06\%. It has decreased tremendously in the past 7 years: to $12.8 \%$ in 2000 , $0 \%$ in 2003-2006 ( $p<0.005)$. Causes of mortality were sepsis, intractable stenosis of aortic arch arteries or pulmonary arteries, recoarctation and heart failure. Between stages, 5 patients died, 3 before second-stage palliation and 2 between stages II and III. One patient underwent heart transplantation after stage II (heart failure). Among 39 Norwood survivors who survived to undergo stage III, there were no early or late deaths. None had signs of heart failure. All had a body weight increase, albeit slowly, and an increase in statomotoric development; all lived at home.

Conclusion: We identified an improvement in outcome after staged surgical management of HLHS, primarily attributable to our increasing experience and surgical expertise. Results showed that three-step palliation is a realistic option for infants with HLHS.

P-6

Preservation of right ventricular function after transatrial-transpulmonary repair of tetralogy of Fallot: a nine year experience

N.M. Giannopoulos, A.C. Chatzis, A.J.Tsoutsinos, F. Kakkava, M. Kantzis, C.A.Contrafouris, M. Mylonakis, D. Bobos, C. Panayotou, P. Zavaropoulos, P. Maraki, I. Sofianidou, E. Kousi, G. Kirvassilis, G.E. Sarris 
Department of Pediatric and Congenital Heart Surgery, Onassis Cardiac Surgery Center, Athens, Greece

E-mail:gsarris@hol.gr

Objective: Our objective is to analyze the outcome of our policy of transatrial-transpulmonary (TA/TP) repair for all patients with TOF over a nine year period, with emphasis on assessment of RV function. Methods: All 183 consecutive patients with TOF referred for repair between 9/1997 and 9/2007 have been prospectively followed and their clinical and echocardiographic data have been retrospectively analyzed. Of these, 178 patients (including 13 with double outlet right ventricle and 5 with anomalous LAD from RCA) underwent complete TA/TP repair at median age 18 months (range 5.5 months to 45 years), including all 11 patients who had undergone palliative shunting elsewhere, and 5 of 10 patients who have had shunts at our institution.

Results: Operative mortality for repair and shunting was zero. Median duration of hospitalization was 11 days. Late follow-up (mean $3.9 \pm 2.8$ years) was $100 \%$ complete. There are no late deaths. One late reoperation was needed 5 years postoperatively for progressive mitral insufficiency related to mitral valve cleft. All patients remain asymptomatic. No significant arrhythmias have occurred. Median residual RVOT gradient $(21 \pm 14 \mathrm{mmHg})$, grade of PI ( $62 \%$ of patients: $0-1+, 24 \%: 2+$ ), grade of tricuspid insufficiency (71\% of patients: $0-1+, 24 \%: 2+$ ), and RV functional score (93.5\%: normal) have remained stable compared with immediate pre-discharge levels.

Conclusion: A policy of TA/TP repair for all patients with TOF is associated with remarkably low mortality and morbidity both early and late, minimal reoperation rate, and excellent late clinical outcome with preservation of RV functional parameters.

\section{P-7}

High near infra-red spectroscopy values further elucidated

S. Hill, C. Rohlicek, J. Lavoie, G. Dougherty, C. Tchervenkov

The Montreal Children's Hospital, McGill University, Montreal, Canada E-mail:Samantha.hill@mail.mcgill.ca

Background: Near Infra-Red Spectroscopy (NIRS), to measure cerebral tissue oxygen content, has been proposed as an intra-operative neuromonitoring technique to improve neurological outcome following congenital cardiac surgery. The focus has been on avoiding low NIRS measurments. High NIRS measurements however, may represent a harmful excess in cerebral oxygen delivery. We have previously presented data showing high NIRS values to be correlated with $\mathrm{p}_{\mathrm{a}} \mathrm{CO}_{2}$; most of these events occur before or after the patient is placed on cardiopulmonary bypass.

Methods: In 60 consecutive bypass congenital cardiac cases, data on predictor variables $\left(\mathrm{pH}, \mathrm{p}_{\mathrm{a}} \mathrm{CO}_{2}, \mathrm{p}_{\mathrm{a}} \mathrm{O}_{2}\right.$, hematocrit, temperature, mean arterial pressure (MAP), and indexed pump flow) was collected. Logistic regression was used to model the dichotomous outcome variable (i.e. an increase in NIRS reading).

Results: In univariate models, $\mathrm{p}_{\mathrm{a}} \mathrm{O}_{2}, \mathrm{p}_{\mathrm{a}} \mathrm{CO}_{2}$, and hematocrit were all significantly associated with high NIRS values. On multivariate analysis, only mean arterial pressure was found to be an independent predictor of high NIRS values. The coefficient for MAP was 0.077. A 1 unit increase in MAP was associated with a 10\% increase in the odds of a significant increase in NIRS reading (CI 1.06, 1.159). Furthermore, nearly $50 \%$ occur following significant decreases.

Conclusion: Significant increases in NIRS are an understudied phenomenon that occur in a majority of patients. The relationships between $\mathrm{p}_{\mathrm{a}} \mathrm{O}_{2}, \mathrm{p}_{\mathrm{a}} \mathrm{CO}_{2}$, hematocrit and NIRS are highly correlated. When corrected for this correlation, mean arterial pressure remains the only independent predictor variable. Furthermore, many events follow periods of relative oxygen deficit, and may represent a compensatory response.

P-8

Effect of selective cerebral perfusion with different temperatures on cerebral metabolism

G. Hoffmann, E. Cavus, R. Quaden, B. Bein, A. Böning, J. Cremer

Department of Cardiac and Vascular Surgery, University of

Schleswig-Holstein, Campus Kiel, Kiel, Germany

E-mail: Grischa.Hoffmann@gmx.de

Objective: During pediatric cardiac surgery selective cerebral perfusion (SCP) provide better cerebral protection than deep hypothermic arrest (DHCA). It remains unclear which temperature of SCP assures best neuroprotection

Methods: To investigate the effects of selective cerebral perfusion on cerebral metabolism twenty-eight pigs $(9.2 \pm 2.1 \mathrm{~kg})$ were randomized to $\mathrm{SCP}$ at $18^{\circ} \mathrm{C}\left(\mathrm{SCP} 18^{\circ}, \mathrm{n}=11\right), 27^{\circ} \mathrm{C}(\mathrm{SCP} 27$, $\mathrm{n}=10)$ or $36^{\circ} \mathrm{C}(\mathrm{SCP} 36, \mathrm{n}=7)$. Systemic cooling on bypass was followed by 90 minutes of SCP with $20 \mathrm{ml} / \mathrm{kg} / \mathrm{min}$ and 30 minutes rewarming. Using arterial and sagittal sinus blood sampling, cerebral metabolism oxygen (CMRO2), glucose (CMR-gluc) and lactate (CMR-lac) was assessed.

Results: CMRO2 decreased far more with SCP18 (24.4 \pm 24.3 of baseline after cooling and 10.2 \pm 10.7 after low flow) than with SCP $27(72.9 \pm 65.3 \%$ and $16.9 \pm 10.9 \%)$ and SCP36 $(87.8 \pm 15.4 \%$ and $43.4 \pm 29.6 \%)$. CMR-gluc followed a similar pattern in all groups but was more pronounced with SCP18 $(23.4 \pm 16.1 \%$ of baseline and $23.3 \pm 30.3 \%$ after low flow) in comparison to SCP27 $(35.9 \pm 21.8 \%$ and $19.8 \pm 16.8 \%)$ and SCP36 (36.3 $\pm 16 \%$ and $12.5 \pm 10.2 \%)$. CMR-lac was mainly lactate production during cooling in all groups, while after warming the lactate production was more pronounced with SCP27 and SCP36 than with SCP18 (220 $\pm 58.9 \%$ and $350 \pm 50 \%$ versus $192 \pm 164 \%$ of baseline). Conclusion: Our results suggest that cerebral protection with SCP at $18^{\circ}$ is superior to $\mathrm{SCP}$ at $27^{\circ}$ and $36^{\circ} \mathrm{C}$. The reduction $\mathrm{CMRO}$, $\mathrm{CMR}$-gluc and lactate production shows that SCP with $18^{\circ} \mathrm{C}$ was the safest method of cerebral protection.

\section{P-9}

Tetralogy of Fallot repair with homograft monocusp valve: factors related to the durability based on mid- to long-term outcome

T.-G. Jun, J.-H.Yang, P.W. Park

Samsung Medical Center, Sungkyunkwan University School of

Medicine, Seoul, Korea

E-mail:bestsurgeon@gmail.com

Purpose: We have performed TOF repair with a homograft monocusp when a transannular patch was required. The aim of this study is to evaluate the long-term outcome and to identify the determinants of its durability.

Methods: Among 244 TOF repair performed between July 1996 and June 2005 at our institution, 54 patients had a homograft monocusp. Four patients were associated with absent pulmonary valve syndrome, 3 patients with pulmonary valve atresia, and 1 with complete AVSD. The median body weight at surgery was 7.8 (range; $3.9 \sim 42) \mathrm{kg}$. The function of the monocusp valve was assessed by regular echocardiograghy. Kaplan-Meier method and Cox regression model were used for statistical analyses.

Results: There were 2 early deaths (3.7\%), which were associated with respiratory infection. No late deaths were observed during 
follow-up ranging from 0.3 to 120 (median, 64.3) months. Freedom from valve dysfunction was $67.2 \pm 6.7 \%$ at 1 year, $37.1 \pm 7.3 \%$ at 3 years, $23.8 \pm 6.7 \%$ at 5 years, and $21.2 \pm 6.4 \%$ at 7 years. One patient underwent pulmonary valve replacement during follow up. ABO incompatibility, branch PA stenosis, and combined absent pulmonary valve syndrome affected the monocusp function statistically.

Conclusion: Homograft monocusp in TOF repair can provide better clinical outcomes in terms of the preservation of valve function. In our experiences, the grafts did not show significant stenosis, but valve insufficiency with degeneration was observed as time passing by. The role of pulmonary valve function in the early postoperative period is to be defined.

\section{P-10 \\ Primary early correction of tetralogy of Fallot irrespective of age \\ A. Kántorová ${ }^{3}$, H. Sauer ${ }^{1}$, C. Lilje ${ }^{2}$, C. Haun ${ }^{1}$, V. Hraška ${ }^{1}$ \\ ${ }^{1}$ German Paediatric Heart Centre, Sankt Augustin, Germany; \\ ${ }^{2}$ University Hospital Hamburg-Eppendorf, Hamburg, Germany; ${ }^{3}$ Slovak \\ Paediatric Heart Centre, Bratislava, Slovakia \\ E-mail:kantorova@dkc-sr.sk}

Objective: Performing an early total repair of tetralogy of Fallot (TOF) irrespective of age or placing a palliative systemic-to-pulmonary shunt remains controversial. The aim of the study was to analyze the mid-term outcome of primary early correction of TOF. Methods: Between 1996 and 2005, a total of 61 consecutive patients less than 6 months of age, underwent primary correction of TOF in two institutions involved in the study. The median age at surgery was 3.3 months, 27 pts (44\%) were $<3$ months of age including 12 (20\%) newborns. The median weight was $4.6 \mathrm{~kg}$ (from 2.3 to 10 ). Two groups were analyzed: I. pts $<3$ months; II. pts between 3 and 6 months of age.

Results: There was one early (1.6\%) and one late death. Actuarial survival was $98.4 \%, 96.7 \%, 96.7 \%$ at 1,5 and 10 years respectively with a median follow up of 4.5 years. There was no difference in survival, bypass time, lengths of ventilation and hospital stay between the two groups. The transanular patch was used significantly more often in group I. The freedom from re-do (including re-interventions) was $96.7 \%$ at 1 year and $86.8 \%$ at 5 years of FU with no difference between the two groups. There were no clinically apparent neurological problems during the FU. Patients are doing well and growth is adequate.

Conclusion: Primary repair of TOF, irrespective of age, provides excellent mid-term outcome with a low mortality and acceptable morbidity. Primary early correction of TOF is the method of choice in our institution.

\section{P-11}

Left heart valve replacement with mechanical prostheses in children: a twenty year experience

S.J.-A. Lloyd, L.U. Nwakanma, E.S. Weiss, K.W. Holmes,

W.A. Baumgartner, L.A.Vricella, D.E. Cameron

Johns Hopkins University, Baltimore, Maryland, USA

E-mail:Ivrice2@ssurg.jhmi.jhu.edu

Background: When repair is not possible, replacement of the aortic and mitral valves with mechanical prostheses in children is often the only option for a durable valve substitute. This study reviewed early and late outcomes of mitral (MVR) and/or aortic (AVR) valve replacement with mechanical prostheses in children.
Methods: Retrospective review of pediatric patients (age $\leqslant 18$ years) who underwent aortic and/or mitral replacement with mechanical prostheses at a single institution between 1985 and 2005. Endpoints included mortality, stroke, freedom from reoperation, thrombosis, hemorrhage and endocarditis.

Results: Ninety-one pediatric patients underwent MVR and/or AVR with mechanical prostheses during the twenty-year study period. Complete clinical follow-up was available for 86 pts (94.5\%) and median follow-up was 75 months (range 2-253 months). Mean age and weight at operation were $11 \pm 6$ years (range $0.2-18$ years) and $43 \pm 27 \mathrm{~kg}$ (range $4-114 \mathrm{~kg}$ ), respectively. Reoperations comprised $8.8 \%$ of all procedures. Operative and late mortality were $4.4 \%$ and $11.0 \%$. Actuarial survival at 1, 5 and 10 years was $92 \%, 90 \%$ and $88 \%$. Of 86 hospital survivors, three (3.3\%) suffered neurological events with permanent deficit, and $13(15.1 \%)$ required valve rereplacement at a mean time to reoperation of 9 years. Nine of 86 hospital survivors $(10.5 \%)$ had anticoagulant-related hemorrhage and 9 had partial prosthetic thrombosis but only one required rereplacement (1.1\%). Five of the 86 children (5.8\%) developed postoperative endocarditis, which lead to valve replacement in $2(2.3 \%)$ Conclusions: MVR and/or AVR in children has low early and late mortality as well as relatively low rate of stroke, reoperation, thrombosis and endocarditis at long-term follow-up. Although valve repair should always be considered the preferred initial approach to left heart valve pathology in children, replacement with a mechanical prosthesis remains a safe and valid alternative.

\section{P-12}

Does cardioplegia leave room for postconditioning in pediatric cardiac surgery?

W. Luo, B. Li, G. Lin, R. Chen, R. Huang

Department of Cardiothoracic Surgery, Xiang Ya Hospital,

Central South University, Changsha, Hunan, China

E-mail:luowanjun@yahoo.com

Background: Postconditioning by brief episodes of ischemia performed just at the time of reperfusion can reduce infarct size in animal model and clinical setting of PCI. However, the clinical applicability of postconditioning in cardiac surgery remains to be determined .In this prospective, randomized, controlled study; we investigated the effect of postconditioning on myocardial protection in children undergoing cardiac surgery.

Methods: Forty patients scheduled for congenital heart defects surgery under cold blood cardioplegic arrest were randomly assigned to postconditioning $(\mathrm{n}=20)$ or control treatment $(\mathrm{n}=20)$. Postconditioning was performed by two cycles of $30 \mathrm{~s}$ ischemia and 30 s reperfusion using aortic reclamping and declamping started $30 \mathrm{~s}$ after cardioplegic arrest. The creatine kinase-MB, troponin I, transcardiac release of lactate were assayed. Measurements of clinical results were taken during the study.

Results: The types of procedure, age, bypass and aortic cross-clamping times were similar in both groups. The postoperative peak creatine kinase-MB and $\mathrm{cTnI}$ were lower after aortic de-clamping in the postconditioning patients compared with control $(128 \pm 48 \mathrm{U} / 1$ vs. $199 \pm 79 \mathrm{U} / \mathrm{l}, \mathrm{p}=0.016$, and $0.34 \pm 0.21 \mathrm{ng} / \mathrm{ml}$ vs. $0.61 \pm 0.53 \mathrm{ng} / \mathrm{ml}, \mathrm{p}=0.05)$ with reduced inotrope in postconditioning group compared with control group (4.3 \pm 3.4 vs. $2.3 \pm 2.1 \mu \mathrm{g} / \mathrm{min} / \mathrm{kg}, \mathrm{p}=0.049)$. Transcardiac release of lactate were reduced in postconditioning group compared with control $(0.10 \pm 0.27 \mathrm{mmol} / 1$ vs. $0.37 \pm 0.43 \mathrm{mmol} / 1, \mathrm{p}=0.048)$.

Conclusions: The present study demonstrated for the first time that postconditioning protects pediatric myocardium undergoing cold blood cardioplegic arrest. These data support the need for a larger clinical trial of postconditiong in children undergoing cardiac surgery. 


\section{P-13}

Creation of a pediatric and congenital heart surgery outcomes database for developing nations

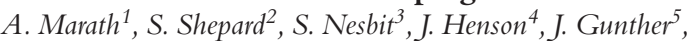
L. Shaftel ${ }^{6}$, E. Morla ${ }^{7}$, P. Barach ${ }^{8}$, J.P. Jacobs ${ }^{9}$

${ }^{1}$ CardioStart International, Tampa, FL, USA $;{ }^{2}$ Rady Children's

Hospital, San Diego, CA, USA; ${ }^{3}$ CardioStart, Chicago, IL, USA; ${ }^{4}$ CardioStart, Philadelphia, MN, USA; ${ }^{5}$ American Nursing Council, Chicago, IL, USA; ${ }^{6}$ Data Collator, Atlanta, GA, USA $;{ }^{7}$ Hospital Del Nino, Lima, Peru; ${ }^{8}$ Faculty of Anesthesia, University of Miami, FL, USA; ${ }^{9}$ The Congenital Heart Institute of Florida (CHIF), University of South Florida (USF), Saint Petersburg, FL, USA

E-mail:aubyn.marath@mac.com

Pediatric cardiac surgery outcomes in developing countries are woefully varied, with many children having no access. Although those motivated to carry out international cardiac surgery assistance programs in developing countries have altruistic motives, the success of a program is frequently measured by what is left behind after the visiting teams have left. Some programs flounder through personnel or equipment shortcomings, or are incapacitated by civil strife, war, change of government, or severe lack of funding. Others fail because the algorithms of patient management in a highly specialized field are not sufficiently developed to permit consistently successful outcomes. Quality improvement tools have not commonly applied to pediatric heart surgery in developing nations. We have developed an Outcomes Database that is compatible with the EACTS and STS Congenital Heart Database but is designed to function as a quality improvement and educational tool for cardiac surgery programs in developing nations.

CardioStart is a volunteer organization that assists countries with both charitable mission pediatric cardiac surgery and bedside education. CardioStart developed a database designed to assess quality of life outcomes in various categories suited to the realities of living in communities in which even basic necessities of daily living are beyond reach for many and where hospitals function with substantial medical, social, and financial restrictions.

The CardioStart Database aims to improve the lasting clinical and educational outcomes in developing countries. Partnership of this initiative with The World Society for Pediatric and Congenital Heart Surgery is an important next step in this process.

\section{P-14}

Pediatric pacemakers: results of a collaborative electrophysiology-surgery program

C. Mavroudis, C.L. Backer, A.M. Kelle, R.D. Stewart, S. Tsao, W.H. Franklin, B.J. Deal

Divisions of Cardiovascular-Thoracic Surgery and Cardiology, Department of Surgery, Northwestern University Feinberg School of

Medicine, Children's Memorial Hospital, Chicago, Illinois, USA

E-mail:PHeraty@childrensmemorial.org

Objective: The purpose of this review was to evaluate the results of pediatric pacemaker placement in a collaborative program where surgeons implant the pacemakers and electrophysiologists provide diagnostic and programming support.

Methods: The cardiac surgery database was used to identify patients having a pacemaker placement for congenital heart disease from 1988-2005. All charts were then reviewed. A total of 523 patients underwent 770 procedures. This included 327 epicardial pacemakers, 166 transvenous pacemakers, 47 AICDs, 135 generator changes, 685 epicardial leads, 318 transvenous leads, and 27 transmural leads.
Results: Age at the time of initial pacemaker placement ranged from 1 day to 48 years (mean age was 12.5 years). Nine patients died within 30 days, all due to severe underlying congenital heart disease. There were 2 infections in 770 operations (.26\%). There were 39 patients who required 40 reoperations within 60 days (5.1\%). The most common was lead repositioning after transvenous pacemaker (16 of 208, 7.7\%). Epicardial lead revision was required in 7 patients (7 of 327, 2.1\%). Minor complications (hematoma, pericardial effusion, pneumothorax, arrhythmia) occurred in 12 patients. Conclusions: Pacemaker placement for patients with congenital heart disease in a collaborative program with implants performed by surgeons and diagnostic and programming provided by pediatric electrophysiologists results in excellent patient outcome with very low infection, mortality, and reoperation rates.

\section{P-15}

Factors associated with incomplete implementation of universal operating room extubation protocol after open heart surgery for congenital heart disease

A.J.C. Mittnacht ${ }^{1}$, K. Nguyen ${ }^{3}$, U. Joash ${ }^{2}$, I.A. Parness ${ }^{2}$, S. Hossain ${ }^{1}$, I. Hollinger $^{1}$

The Mount Sinai Medical Center, NY, New York, USA

Department of Anesthesiology ${ }^{1}$, Division of Pediatric Cardiology ${ }^{2}$, Department of Cardiothoracic Surgery ${ }^{3}$

E-mail:Alexander.Mittnacht@msnyuhealth.org

Introduction: We instituted a protocol of attempting operating room (OR) extubation immediately after surgery for congenital heart disease (CHD). This study investigated perioperative factors associated with deciding not to proceed with rapid OR extubation. Materials and Methods: Retrospective database analysis of pediatric patients undergoing surgery for CHD using cardiopulmonary bypass (CPB) at The Mount Sinai Medical Center between July 2002 and May 2005. Inclusion criteria: age 1 month-18 years, and not intubated preoperatively. Surgical procedure complexity was not a selection criterion. 224 patients met selection criteria. For univariate analyses, Chi-square or Fisher's Exact Tests were used as appropriate. The independent influence of various patient and perioperative characteristics on outcome was tested using a Stepwise Logistic Regression.

The table below shows the probability [and 95\% confidence intervals] of not proceeding with planned OR extubation grouped by combinations of independent variables including inotrope score (INO):

\begin{tabular}{|c|c|c|c|c|c|c|}
\hline & \multicolumn{2}{|c|}{$<6$ months } & \multicolumn{2}{|c|}{ 6-11.9 months } & \multicolumn{2}{|c|}{$\geqslant 12$ months } \\
\hline & Female & Male & Female & Male & Female & Male \\
\hline \multicolumn{7}{|c|}{ Bypass $<150$ minutes: } \\
\hline \multirow[t]{2}{*}{ INO $<5$} & 0.15 & 0.33 & 0.05 & 0.11 & 0.01 & 0.03 \\
\hline & {$[0.06,0.34]$} & {$[0.17,0.53]$} & {$[0.02,0.12]$} & {$[0.05,0.21]$} & {$[.003,0.04]$} & {$[0.01,0.08]$} \\
\hline \multirow[t]{2}{*}{ INO 5-9 } & 0.2 & 0.40 & 0.06 & 0.14 & 0.02 & 0.04 \\
\hline & {$[0.08,0.41]$} & {$[0.21,0.62]$} & {$[0.02,0.15]$} & {$[0.06,0.29]$} & {$[.004,0.06]$} & {$[0.01,0.12]$} \\
\hline \multirow[t]{2}{*}{ INO $10-15$} & 0.43 & 0.66 & 0.16 & 0.33 & 0.05 & 0.11 \\
\hline & {$[0.23,0.65]$} & {$[0.46,0.82]$} & {$[0.07,0.33]$} & {$[0.18,0.53]$} & {$[0.01$,} & {$[0.04$,} \\
\hline \multicolumn{7}{|c|}{ Bypass $\geqslant 150$ minutes: } \\
\hline \multirow[t]{2}{*}{$\mathrm{INO}<5$} & 0.72 & 0.87 & 0.40 & 0.63 & 0.14 & 0.31 \\
\hline & {$[0.36,0.92]$} & {$[0.61,0.97]$} & {$[0.15,0.71]$} & {$[0.34,0.86]$} & {$[0.04,0.37]$} & {$[0.12,0.58$} \\
\hline \multirow[t]{2}{*}{ INO 5-9 } & 0.78 & 0.90 & 0.47 & 0.70 & 0.18 & 0.37 \\
\hline & {$[0.47,0.93]$} & {$[0.70,0.97]$} & {$[0.22,0.74]$} & {$[0.43,0.88]$} & {$[0.06,0.42]$} & {$[0.16,0.64]$} \\
\hline \multirow[t]{2}{*}{ INO $10-15$} & 0.91 & 0.96 & 0.72 & 0.87 & 0.40 & 0.64 \\
\hline & {$[0.73,0.98]$} & {$[0.87,0.99]$} & {$[0.46,0.88]$} & {$[0.70,0.95]$} & {$[0.18,0.67]$} & {$[0.37,0.84]$} \\
\hline
\end{tabular}


Results: Overall, 79\% (178/224) of patients (ages 1 month-18 years, median 20 months) were extubated in the OR. In univariate analysis, all studied factors (except for reoperation) were significantly associated with outcome. Multiple Logistic Regression identified younger age and longer $\mathrm{CPB}$ time as the strongest predictors for not rapidly extubating. Males and higher inotrope score were also significantly associated with outcome. No OR extubated patients needed re-intubation for respiratory insufficiency.

Conclusions: Rapid extubation in the OR after surgery for CHD was successful in the majority of CPB patients meeting the above selection criteria, even in infants and after complex procedures. Younger males with longer bypass time and high inotrope score had the least probability of attempted OR extubation.

\section{P-16}

Defining the role of arginine-vasopressin in congenital

heart surgery

D.L.S. Morales, J. Booth, K.A. Arrington, E.D. McKenzie,

H.A. Dickerson, C.D. Fraser, Jr, J.S. Heinle

Division of Congenital Heart Surgery, Texas Children's Hospital,

Houston, Texas, USA

E-mail:dlmorale@TexasChildrensHospital.org

Background: Postcardiotomy vasodilatory shock in the pediatric population is being treated successfully with arginine-vasopressin (AVP). Well-documented is the increase in endogenous AVP levels stimulated by hypotension. However, in adults prolonged episodes of hypotension can lead to a physiologic depletion of this hormone and it is only then that exogenous AVP administration has been shown to be an effective vasopressor. Therefore, we prospectively studied the effects of AVP administration in neonates with postcardiopulmonary bypass (CBP) hypotension and correlated these effects with plasma AVP levels.

Methods: Twelve neonates undergoing cardiac surgery at Texas Children's Hospital between 7/2005 and 12/2006 were studied. Median age; weight: 7 days (3-28d); $2.8 \mathrm{~kg}(2.1-4.1 \mathrm{~kg})$. All patients received AVP within 12-hours post-CPB. Doses ranged from 0.01 to $0.04 \mathrm{U} / \mathrm{kg} / \mathrm{hr}$. As per their normal practice, the attending physician decided when to administer AVP.

Results: Despite remaining severely hypotensive and on significant inotropes, 10 patients who had increased their mean AVP level to $38.2 \pm 33 \mathrm{pg} / \mathrm{ml}$ demonstrated a relative AVP depletion to $8.6 \pm 15 \mathrm{pg} / \mathrm{ml}(\mathrm{p}<.05)$. AVP administration increased their levels from $8.6 \pm 15$ to $48.9 \pm 36 \mathrm{pg} / \mathrm{ml}(\mathrm{p}<.01)$, their systolic blood pressure (BP) from $48 \pm 6 \rightarrow 74 \pm 14 \mathrm{mmHg}(\mathrm{p}<.001)$, and their diastolic BP from $30 \pm 4 \rightarrow 39 \pm 7 \mathrm{mmHg}(\mathrm{p}<.01)$, while the inotropic score $(16 \pm 6 \rightarrow 15 \pm 5, p>0.05)$ did not change. Despite being hypotensive, 2 patients did not show any increased AVP levels post-CPB (all AVP levels $<4.5 \mathrm{pg} / \mathrm{ml}$ ) and thus did not increase BP $(52 / 34 \rightarrow 56 / 34 ; 37 / 33 \rightarrow 40 / 28 \mathrm{mmHg})$ when administered AVP. Hospital survival was 100\%.

Conclusion: Previously in adults and now in neonates, postcardiotomy vasodilatory hypotension resistant to catecholamines is associated with a relative AVP deficiency. It is in these patients that exogenous AVP administration is effective in improving hemodynamics.

\section{P-17}

The use of intratissular biodegradable rings in atrio-ventricular valve reconstruction

W. Mrówczynski ${ }^{1}$, B. Mrozinski ${ }^{2}$, M. Wojtalik ${ }^{1}$, A. Kalangos ${ }^{3}$

Departments of ${ }^{1}$ Paediatric Cardiac Surgery and ${ }^{2}$ Paediatric Cardiology, Poznan University of Medical Sciences, Szpitalna Poznan, Poland,

${ }^{3}$ Clinique de Chirurgie Cardio Vasculaire, HCUG, Geneva, Switezerland E-mail:wjmrow@amp.edu.pl
Aims: Preliminary results of biodegradable rings application during reconstruction of A-V valves are reported.

Material: In period from 2005-06-01 to 2006-12-21 18 children were operated for severe insufficiency of A-V valves: Ebstein's anomaly -6 p., TI -7 p., MI -5 p. Median age was 13.6 years $(1.3-18.5$ years).

Methods: Type of procedure depended on specific CHD including valve reconstruction with the use of biodegradable ring. All patients were followed-up by TTE at discharge and 1.6 and 12 months after the procedure.

Results: No early and late deaths were observed. ECC time was $93 \mathrm{~min}(37-230 \mathrm{~min})$, aortic cross-clamp time was $49 \mathrm{~min}$ (0-120 min). Implanted ring diameters were from 18 to $34 \mathrm{~mm}$. Median follow-up time was 190 days (7-367 days). Tricuspid insufficiency fraction dropped ( $\mathrm{p}<0.05)$ from 39.2\% (15.6-93\%) to $11.1 \%(0-28.8 \%)$ at discharge and was respectively $14 \%$ (3-40.6\%), 16.5\% (7.5-29\%) and $11.7 \%(5.8-22 \%)$ at 1.6 and 12 months after the operation. Mitral insufficiency fraction decreased $(\mathrm{p}<0.05)$ from $67 \%(37.2-80 \%)$ to $9.5 \%(4.9-50 \%)$ at discharge and was respectively $8 \%(4.9-15 \%)$ and $13.7 \%(10.4-17 \%)$ at 1 and 6 months after the operation. No pressure gradient across corrected valve exceeded $10 \mathrm{mmHg}$ throughout entire follow-up.

Conclusions: The implantation of biodegradable rings is safe. Enables easy reinforcement of the native annulus. Ring implantation decreases operation time. Early and short-term results are good in the context of corrected congenital heart defect spectrum.

\section{P-18}

Routine leaflet augmentation of left atrioventricular valve in the repair of atrioventricular septal defect H.K. Najm, M. Godman

King Abdulaziz Cardiac Center, Riyadh, Saudi Arabia

E-mail:haninajm@hotmail.com

Objectives: A better understanding of the morphology of complete atrioventricular septal defects (CAVSD) has impacted on surgical techniques and results. On some occasions the leaflet tissue is deficient and repair becomes difficult.

Methods: The technique was performed on 85 infants with CAVSD at a mean age of $5 \pm 1.3$ months. Five were associated with Tetralogy of Fallot. Both superior and inferior bridging leaflets are divided routinely to expose the VSD. An autologous pericardial patch, sized precisely, is sutured to the ventricular septum. A 3-4 mm of extra patch is fashioned beyond the plane of the annulus and sutured to the divided leaflet of the left atrioventricular valve (AVV). A second autologous pericardial atrial patch is attached to the body of the VSD patch at the plane of the annulus allowing 3-4 mm of the VSD patch to augment the left AV valve.

Results: There were no early deaths among these infants. At early postoperative echo all infants had no significant residual lesions. The contribution of the patch-augmented left AV valve to competency is clearly seen by $2 \mathrm{D}$ echocardiography. At a mean follow up of $45 \pm 10$ months there was two late deaths with normal last echocardiography. There were only two children who progressed to severe left $\mathrm{AV}$ valve regurgitation needing reoperation. Conclusions: This modified technique yields good anatomical repair. Allowing reconstruction of both AV valves independent of the other and is in particular helpful in cases of deficient left AVV tissue.

P-19

Predictors of survival of Fontan operation in the long term M.A. Padalino ${ }^{1}$, M. Lo Rito ${ }^{1}$, G. Rizzoli ${ }^{1}$, R. Biffanti ${ }^{2}$, O. Milanesi ${ }^{2}$, G. Stellin ${ }^{1}$ 
Pediatric Cardiac Surgery ${ }^{1}$ and Pediatric Cardiology ${ }^{2}$, University of Padova Medical School, Padova, Italy

E-mail: Massimo.padalino@unipd.it

Objective: To assess predictors of mortality in patients with various different forms of functional single ventricle after Fontan operation in a 20 years time frame.

Methods: Patients who underwent Fontan-type operation between 1985 and 2005 were submitted to a retrospective analysis of medical records, clinical and instrumental assessment. Excluded were redo Fontan, and one and a half ventricle repair. Follow up data were obtained from cardiology follow up controls. Statistical analysis was done with statistical programme Stata 9.1.

Results: 116 patients underwent a Fontan operation $(\mathrm{M} / \mathrm{F}=70 / 46)$. Mean age at operation was 4.5 years (median 2.99, range 0.98-32.85 years). Main cardiac malformations were 132 (tricuspid atresia 35, DORV 25, PAIVS 22, DILV 21, HLHS 15, unbalanced AV septal defect 12, HLHC 1, Ebstein anomaly 1). Fontan circulation was staged in 59.5\% (BDG in 50, hemifontan in 13, BBDG in 6). The Fontan type procedure was completed with atriopulmonary or atrio-infundibular anastomosis in 29, intra-atrial flap in 6 , extracardiac conduit (EC) in 31, a lateral tunnel (LT) in 50 pts. Fenestration was performed in 55 patients.

Early mortality (<30 days) decreased from $22 \%(1985-1991)$ to $2.5 \%$ (1992-2005).

At a mean follow up of 7.6 years ( range 4 months-20.7 years, 94\% completeness), 10 patients had a failed Fontan, 8 died late after Fontan. Late mortality decreased from $11 \%(1985-1991)$ to $5 \%$ (1992-2005).

While prolonged ventilation and atriopulmonary connection are correlated with a high risk for global mortality ( $\mathrm{p}$-value $\leqslant 0,05$ ), total cavopulmonary connection, staged approach and fenestration (Odds Ratio 0.10) are inversely related to global survival $(\mathrm{p}$-value $\leqslant 0.05)$.

Conclusions: Fontan circulation has become a satisfactory long term palliation for functional single ventricle anomalies, in terms of early and midterm outcome, thanks to patient selection, new techniques and improved expertise.

\section{P-20}

Long-term results of conotruncal repair for tetralogy of Fallot: 20 year Tokyo experience

T. Sakamoto, K. Ishihara, Y. Iwata, G. Matsumura, N.Yamamoto, H. Kurosawa

Department of Cardiovascular Surgery, The Heart Institute of Japan,

Tokyo Women's Medical University, Tokyo, Japan

E-mail:takasakamoto@yahoo.co.jp

Objective: Conotruncal repair for tetralogy of Fallot (TOF) was introduced in 1985 to achieve low CVP, no heart murmur, and no conduction disturbance. The purpose of this study was to evaluate the long-term results of this procedure.

Patients and Methods: One hundred forty-three (143) TOF patients underwent conotruncal repair with hand-made monocuspid patch between October 1985 and January 1991. Patients with pulmonary atresia were excluded. The age of patients ranged from 2 months to 27 years (mean: 4.2 years).

Results: There was no early death. Two late deaths occurred over a mean follow-up period of 17.8 years (CHF, pneumonia). There were five reoperations (residual PAPVC repair (2), pacemaker implantation for preoperative II AV block (2), residual VSD (1)). No patient required reoperation for residual outflow reconstruction and new onset AV block. Cardiac catheterization in the midterm (1 month-5.7 years) revealed RVp of $49.5 \pm 12.9 \mathrm{mmHg}$, CVP of
$9.0 \pm 2.8 \mathrm{mmHg}$, and CI of $3.8 \pm 0.91 / \mathrm{min} / \mathrm{m}^{2}$. In the longterm period, chest X-ray showed CTR of $51.8 \pm 4.4 \%$, and ECG revealed PQ interval of $0.17 \pm 0.03 \mathrm{msec}$ and QRS of $0.12 \pm$ $0.03 \mathrm{msec}$. All patients were in sinus rhythm, except for 4 patients of I AV block, and 3 of II AV block. Echocardiogram showed RV outflow pressure gradient of $16.7 \pm 9.0 \mathrm{mmHg}$, estimated $\mathrm{RVp}$ of $39.9 \pm 8.1 \mathrm{mmHg}$, moderate PR in 25 patients, and moderate TR in 2. All patients were in NYHA class I.

Conclusion: Conotruncal repair for TOF has provided excellent long-term outcomes with minimum incidence of morbidity. The further careful observation is mandatory.

\section{P-21}

Spectrum and surgical management of grown-up congenital heart disease in Accra

L.A. Sereboe, F. Edwin, M.M. Tettey, E. Aniteye, D.A. Kotei,

M. Tamatey, K. Entsua-Mensah, V.Amuzu, F. Fonder,

K. Frimpong-Boateng

National Cardiothoracic Centre, Korle-Bu Teaching Hospital, Korle-Bu, Accra, Ghane

E-mail:fedwin68@yahoo.com

One hundred and thirty-one grown-ups who underwent surgery for congenital heart disease between January 1992 and December 2005 form the basis for this paper.

They made up $28.1 \%$ of all congenital heart surgeries performed at our institution in the same 14-year period.

Their case notes and operative records were reviewed. There were 58 males and 74 females $(\mathrm{M}: \mathrm{F}=1: 1.3)$. Their ages ranged from 13-64 years with a mean age of 23.9 years and a median of 20 years.

Using the New York Heart Association (NYHA) functional classification, 33 patients (25.2\%) were in NYHA I, 81 patients (61.8\%) were in NYHA II and $17(13.0 \%)$ patients in NYHA III. Thirty patients $(22.7 \%)$ were discovered incidentally.

Intra-operative findings were classified as left-to-right shunts, right-to-left shunts, obstructive lesions or miscellaneous lesions. Left-to-right shunts accounted for $59 \%$ of the cases.

In all cases requiring cardiopulmonary bypass, the surgical approach was through a median sternotomy except in one female with an ASD in which a right thoracotomy via a sub mammary skin incision was used.

Surgical correction was accomplished with a hospital mortality of $1.5 \%$ and one late death $(0.8 \%)$.

It is concluded that surgery for grown-ups with congenital heart disease can be accomplished with acceptable mortality. Practitioners should be cautious with the performance of routine medical examinations in order not to miss the presence of congenital heart disease in asymptomatic adults.

P-22

Indication for reoperation late after correction of tetralogy of Fallot

T. Tirilomis, R. Seipelt, F.A. Schoendube, W. Ruschewski

Department of Thoracic, Cardiac, and Vascular Surgery, University

Göttingen, Germany

E-mail:theodor.tirilomis@med.uni-goettingen.de

Introduction: Correction of tetralogy of Fallot (TOF) has excellent long-term results. We performed retrospective data analysis to investigate incidence and indications for reoperation late after correction surgery for TOF. 
Methods: In 91 patients out of 914 consecutive patients who underwent surgery for TOF in our departement between 1960 and 2002, 106 reoperations were performed.

Results: The indication for reoperation was: residual ventricular septum defect (VSD; 27.6\%), residual VSD with right ventricular outflow tract (RVOT) aneurysm (12.4\%), residual VSD with pulmonary stenosis (6.7\%), isolated RVOT aneurysm (5.7\%), isolated peripheral pulmonary stenosis $(8.6 \%)$, replacement of primary implanted pulmonary artery conduits (with or without peripheral pulmonary stenosis; $13.3 \%$ ), replacement of the pulmonary valve $(11.4 \%)$, and others (4.8\%).
In the last decade of the study period the rate of residual VSD (with or without concomitant procedures) decreased $(n=4)$.

There was no correlation between the type of corrective surgery and reoperation late after correction.

Conclusions: Reoperation was mostly necessary for residual VSD (with or without concomitant procedures), but with declining incidence during the last decade. Primary use of conduits led to increasing number of reoperations for conduit exchange, due to degeneration or failure. 